\title{
A identificação de anos secos, chuvosos e normais em Machado/MG através do estudo de uma série histórica e análise do comportamento da Precipitação
}

\section{The identification of dry, rainy and normal years in Machado/MG through the study of a historical series and analysis of the behavior of Precipitation}

\author{
Paulo Henrique de Souza \\ Geografia pela UNESP de Rio Claro/SP e Prof. Assoc. na UNIFAL-MG \\ phsouza31@hotmail.com
}

Bruno César dos Santos

Geografia pela UNIFAL-MG e Doutorando em Ciências da Engenharia Ambiental pela EESC/USP bruno-unifal@hotmail.com

Rafael Grecco Sanches Geografia pela USC de Bauru/SP e Doutorando em Ciências da Engenharia Ambiental pela EESC/USP

rafagsanches@usp.br

\section{Resumo}

$\mathrm{Na}$ presente análise foi utilizado tratamento quantitativo dos dados de precipitação diária em duas séries históricas fornecidas respectivamente pela Agência Nacional de Águas (ANA) 1962 a 2017, e, Instituto Nacional de Meteorologia 1991 a 2017. Os dados coletados foram divididos e analisados por meio de tempos sucessivos representativos mensais, sazonais e anuais; posteriormente, foram elaboradas tabelas e gráficos com os registros pluviométricos do período com o intuito de facilitar a visualização da variabilidade pluviométrica. A primeira etapa constituiu-se na tabulação da série histórica, a seguinte ocupou-se com o tratamento estatístico dos dados de precipitação, utilizando-se os respectivos parâmetros - média, desvio-padrão e coeficiente de variação - admitidos para escalas de análise mensal, sazonal e anual. Também foram caracterizados os anos hidrológicos por meio da metodologia da classificação de "anos padrões" proposta por Monteiro (1976), ou seja, as variações próximas ao ritmo "habitual" classificando-as como habitual (Normal) ou atípico (Seco ou Chuvoso). No estudo ainda ficou evidenciada a existência de duas conjunturas atmosféricas ao longo do ano; uma pautada pela constância do comportamento da precipitação, e, outra pela permanente oscilação. Também ficou explícito que os processos atuantes sobre o verão, primavera e outono são mais regulares que aqueles que atuam sobre o inverno. Com essa compreensão, foi possível identificar o padrão atmosférico na área de estudo e o comportamento da precipitação em Machado/MG.

Palavras-chave: Precipitação, Série Histórica, Água, Habitualidade, Oferta Hídrica.

\begin{abstract}
In the present analysis, a quantitative treatment of the data of daily precipitation in two historical series provided respectively by the National Water Agency (ANA) 1962 to 2017, and the National Institute of Meteorology 1991 to 2017. The data collected were divided and analyzed using successive times representative monthly, annual and seasonal; they were subsequently drawn up tables and graphs with rainfall records of the period to facilitate the visualization of rainfall variability. The first step consisted in the tabulation of the historical series, the following occupied himself with the statistical treatment of the data of precipitation, using the respective parameters - mean, standard deviation and coefficient of variation - allowed for scales of analysis monthly, seasonal and annual. Were also characterized the hydrological years through the methodology of classification of years "standards" proposed by Monteiro (1976), i.e., the rhythm variations near the "usual" classifying them as usual (Normal) or atypical (dry or wet). In this study, it was evidenced the existence of two atmospheric environments throughout the year; a guided by the constancy of the behaviour of
\end{abstract}


precipitation, and another by the permanent oscillation. It also became clear that the processes acting over the summer, spring and autumn are more regular than those that act over the winter. With this understanding, it was possible to identify the atmospheric pattern in the study area and the behaviour of precipitation in Machado/MG.

Keywords: Precipitation, Historical Series, Water, Habitual, Water Offering.

\section{INTRODUÇÃO}

A influência exercida pelo clima numa determinada área está ligada ao comportamento dinâmico atmosférico que pode ser identificado através de suas variáveis (temperatura, precipitação, pressão atmosférica, umidade relativa, etc.) e da habitualidade e/ou no ritmo que apresentam, sendo capaz de interferir na paisagem e afetar as relações entre o homem e o ambiente dentro de um determinado espaço-tempo. Obviamente esse padrão atmosférico é definido e estabelecido após a análise dinâmica de suas variáveis climatológicas por uma duração de tempo considerável que permite a identificação dos seus padrões habituais (NIMER, 1979).

Atentando para isto e para a dimensão da ação atmosférica sobre a paisagem, André (2006) entende que o clima exerce uma função destacada na configuração do espaço geográfico e na formação do meio ambiente, tornando-se determinante na disponibilidade de alguns recursos naturais e nas características gerais da paisagem, assim como nos aspectos socioeconômicos e culturais estabelecidos a partir da presença humana numa determinada área.

Dentre as manifestações de um tipo climático, a precipitação, através de sua intensidade e frequência ao longo de um ano, responde por parte dos parâmetros que o descrevem por estar sujeita a conjugação das forças atmosféricas que atuam sobre a superfície terrestre.

Em face disto, os estudos climáticos buscam compreender e avaliar as alterações atmosféricas no planeta, pois, segundo entende Sentelhas e Pereira (2000) p. 106, "As condições climáticas na Terra sofrem flutuações contínuas. Dependendo da escala de tempo em que se trabalha é possível visualizar essa variabilidade e definir o que são mudanças climáticas".

Sob esse embasamento o presente estudo foi desenvolvido, considerando os dados de Precipitação obtidos para o município de Machado/MG, buscando fornecer subsídios que auxiliem na implementação de um planejamento territorial capaz de minimizar os impactos negativos advindos das manifestações atmosférica sobre a área, permitindo que a qualidade de vida da população não seja afetada, bem como o exercício de suas atividades habituais, pois, via de regra, a inexistência de estratégias eficazes de mitigação e preparo para os problemas que as situações de escassez hídrica acabam por estabelecer, tornam essa iniciativa imperativa (CARMO et al., 2014).

Para tanto, a precipitação na área de estudo foi analisada através da metodologia de AnosPadrão e o desvio da média que classifica os períodos em cinco modalidades - Normal, Chuvoso, 
Tendente a Chuvoso, Seco, e, Tendente a Seco; destacando os semestres chuvoso e seco, procurando entender suas tendências.

\section{2. ÁREA DE ESTUDO - DESCRIÇÃO CLIMÁTICA}

O município de Machado está localizado na Mesorregião Sul/Sudoeste de Minas Gerais. Sua localização geográfica (latitude e longitude) e relevo favorecem segundo entende Sá Junior (2009) um padrão climático classificado Temperado Chuvoso Quente com base na classificação de KöppenGeiger (1928), com variação média de temperatura nos meses mais frios do ano entre $-3^{\circ} \mathrm{C}$ e $18^{\circ} \mathrm{C}$ e estações de inverno e verão bem definidas, enquadrando-se no grupo climático C, dividido em duas classes climáticas, a classe Cwa e a classe Cwb. A classe Cwa apresenta um clima temperado úmido com inverno seco e verão quente com a temperatura média do mês mais quente superior a $22^{\circ} \mathrm{C}$, enquanto que a classe $\mathrm{Cwb}$ apresenta um clima temperado úmido com inverno seco, mas a estação do verão temperado ou moderadamente quente com temperatura média do mês mais quente inferior a $22^{\circ} \mathrm{C}$ e temperatura média dos 4 meses mais quentes superiores a $10^{\circ} \mathrm{C}$. A classificação climática na microrregião está organizada em três classes, a Cwa Semi-úmido com temperatura média de $15^{\circ}$ $\mathrm{C}$ a $18^{\circ} \mathrm{C}$ em pelo menos 1 mês do ano e período seco de 4 a 5 meses, a Cwa Úmido com temperatura média de $15^{\circ} \mathrm{C}$ a $18^{\circ} \mathrm{C}$ em pelo menos 1 mês e período seco de 3 meses e a terceira classe climática a Cwb Úmido com temperatura média de $10^{\circ} \mathrm{C}$ a $15^{\circ} \mathrm{C}$ e um período seco de 1 a 2 meses do ano (FUPAI, 2013).

Comumente definido como Clima Tropical de Altitude segundo os parâmetros adotados pela classificação de Strahler, possuindo duas estações pluviométricas definidas ao longo do ano - padrão monçônico típico do Clima Tropical - concentrando a precipitação entre os meses de outubro a março, enquanto a estiagem fica delimitada pelos meses de abril a setembro com episódios esporádicos que amenizam a baixa umidade relativa do ar na área. De igual modo o comportamento térmico segue na mesma padronização, mesmo que as temperaturas de outubro e março não sejam tão elevadas como em dezembro, janeiro e faveiro; assim como as registradas em abril e setembro não sejam frias como aquelas observadas nos meses de junho, julho e agosto.

Por se encontrar no contexto comum e característico do Sul de Minas Gerais, a área tem seu Clima influenciado pela altitude e pelo relevo relativamente acidentado, diferenciando-se ligeiramente da condição verificada, por exemplo, na porção Norte do estado de São Paulo onde a paisagem monótona e menor altitude não promove o mesmo cenário.

Diniz (2016) apresenta um mapa climático da Microrregião de Alfenas onde o município de Machado encontra-se limitado no quadrante UTM composto por 7590000 e 7620000 de latitude, e, 385000 e 430000 de longitude, nos predomínios do Clima Cwa. 


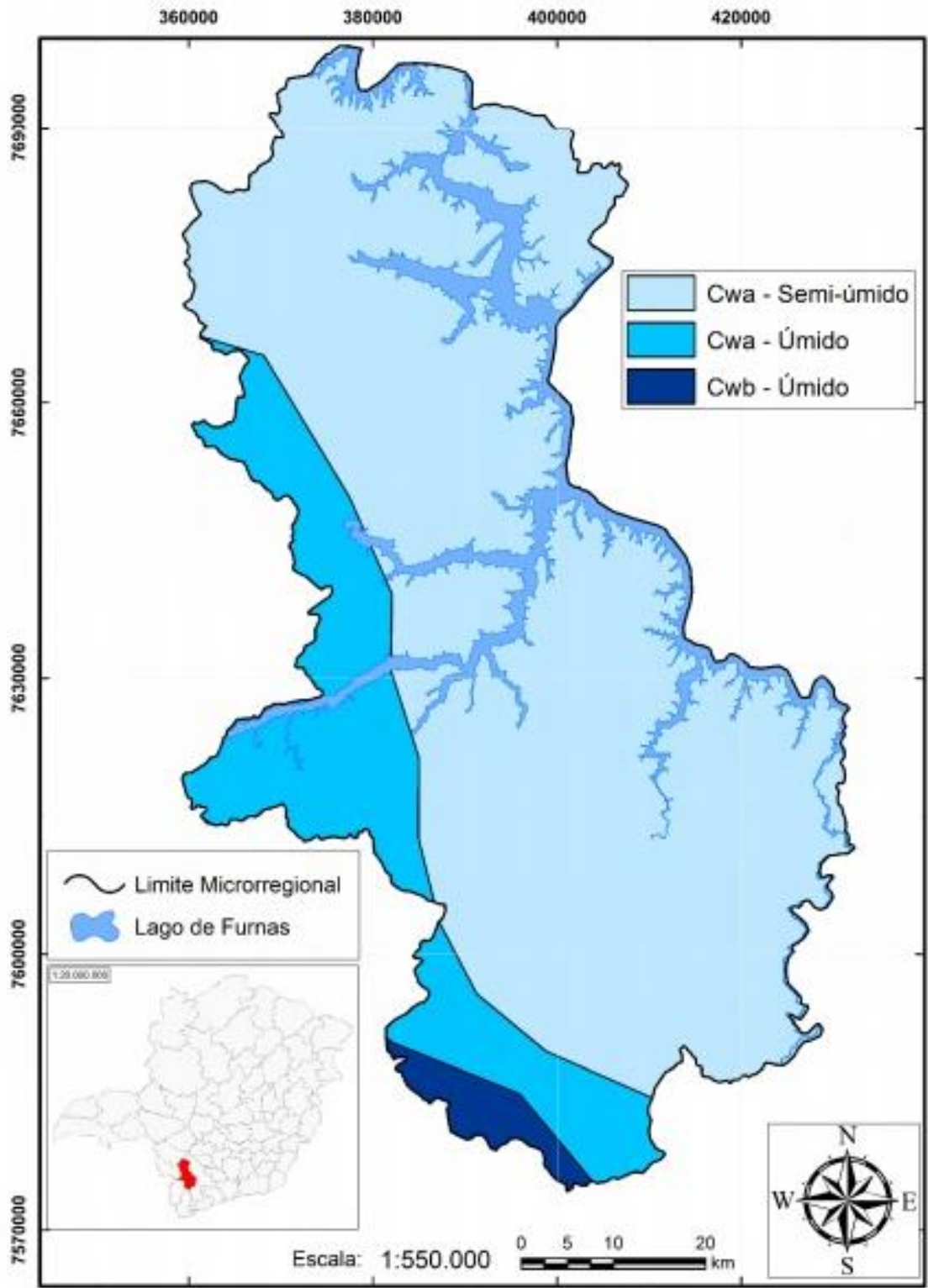

Projecto: Universal Transversa de Mercator - UTM / Zona 23S Datum: SIRGAS 2000 Elaborado por: Douglas Teles Diniz, Discente Geografia Bacharelado Ano: 2016

Figura 1 - Clima da Microrregião de Alfenas.

Fonte - Diniz (2016).

\section{METODOLOGIA}

Na presente análise foi utilizado tratamento quantitativo dos dados de precipitação diária nas séries históricas fornecidas pela Agência Nacional de Águas (1962 a 2017) e Instituto Nacional de Meteorologia (1991 a 2017). Os dados coletados foram divididos e analisados por meio de tempos sucessivos representativos mensais, sazonais e anuais; posteriormente, foram elaboradas tabelas e figuras com os registros pluviométricos do período com o intuito de facilitar a visualização da variabilidade pluviométrica. A primeira etapa constituiu-se na tabulação da série histórica. A etapa seguinte ocupou-se com o tratamento estatístico dos dados de precipitação, utilizando-se os respectivos parâmetros - média, desvio-padrão e coeficiente de variação - admitidos para escalas de 
análise mensal, sazonal e anual. Também foram caracterizados os anos hidrológicos por meio da metodologia da classificação de "anos padrões" proposta por Monteiro (1976), ou seja, "os diferentes graus de proximidade do ritmo "habitual" ao lado daqueles afetados por irregularidades na circulação" (MONTEIRO, 1991, p.38), classificando-os como habitual (Normal) ou atípico (Seco ou Chuvoso), conforme a Tabela 1.

Tabela 1 - Classificação do comportamento pluviométrico.

\begin{tabular}{lr}
\hline Classificação & Desvios (+) ou (-) em \% \\
\hline Normais: & desvios variando entre $+15 \%$ e $-15 \%$ \\
Tendentes a Secos: & desvios negativos oscilando entre $15 \%$ a $30 \%$ \\
Secos: & desvios negativos superiores a $30 \%$ \\
Tendentes a Chuvosos: & desvios positivos oscilando entre $15 \%$ a $30 \%$ \\
Chuvosos: & desvios positivos superiores a $30 \%$ \\
\hline
\end{tabular}

Fonte - Adaptado de Monteiro (1976).

De acordo com Tavares (1976), os valores de precipitação com desvios próximos da média serão considerados anos habituais (normais), e, aqueles com grandes desvios positivos em relação às médias caracterizam anos chuvosos, e, os de grande desvio negativos anos secos. Essa classificação de Anos Padrões já foi utilizada em estudos ocupados com a compreensão do regime pluviométrico em diversos trabalhos (BARBOSA, J. P. M., 2007; BRAIDO ; TOMMASELLI, 2010; MOURA ; ZANELLA, 2012; SILVA ; SILVA, 2012; SOARES ; ZANELLA, 2014).

Cumpre destacar que tal metodologia não discute pontualmente ocorrências que se manifestam em períodos curtos de vinte e quatro horas, recobrando, por conseguinte, uma atenção maior do pesquisador no cuidado de eventos que por vezes possam ser significativos.

\section{ESTUDO DE CASO}

Segundo os dados disponibilizados pela Agência Nacional de Águas, a precipitação média do período foi de 1.541,23 mm. Assim, com base nos dados obtidos (Tabela 2) e na metodologia mencionada anteriormente, foi elaborado a Figura 2 com o enquadramento anual frente ao valor médio da série histórica adotada no estudo, a saber, 1962-2017. 
Tabela 2 - Precipitação anual da Série Histórica (1962-2017).

\begin{tabular}{|c|c|c|c|c|c|c|c|}
\hline ANOS & TOTAL & $\begin{array}{l}\text { MÉDIA } \\
\text { (53 anos) }\end{array}$ & DM & ANOS & TOTAL & $\begin{array}{l}\text { MÉDIA } \\
\text { (53 anos) }\end{array}$ & DM \\
\hline 1962 & 2146 & 1541,260377 & 604,7396 & 1990 & 1059,7 & 1541,260377 & $-481,56$ \\
\hline 1963 & 752,9 & 1541,260377 & $-788,36$ & 1991 & 1762,6 & 1541,260377 & 221,3396 \\
\hline 1964 & 1828,8 & 1541,260377 & 287,5396 & 1992 & 2051,3 & 1541,260377 & 510,0396 \\
\hline 1965 & 2065,1 & 1541,260377 & 523,8396 & 1993 & 1527,4 & 1541,260377 & $-13,8604$ \\
\hline 1966 & 1995,7 & 1541,260377 & 454,4396 & 1994 & 1477,1 & 1541,260377 & $-64,1604$ \\
\hline 1967 & 1370,2 & 1541,260377 & $-171,06$ & 1995 & 1465,7 & 1541,260377 & $-75,5604$ \\
\hline 1968 & 1257,4 & 1541,260377 & $-283,86$ & 1996 & 1831,3 & 1541,260377 & 290,0396 \\
\hline 1969 & 1448,2 & 1541,260377 & $-93,0604$ & 1997 & 1495,5 & 1541,260377 & $-45,7604$ \\
\hline 1970 & 1684,4 & 1541,260377 & 143,1396 & 1998 & 1366,3 & 1541,260377 & $-174,96$ \\
\hline 1971 & - & 1541,260377 & - & 1999 & 1280,8 & 1541,260377 & $-260,46$ \\
\hline 1972 & 1385,1 & 1541,260377 & $-156,16$ & 2000 & 1629,7 & 1541,260377 & 88,43962 \\
\hline 1973 & 1388 & 1541,260377 & $-153,26$ & 2001 & 1200,4 & 1541,260377 & $-340,86$ \\
\hline 1974 & 1073,6 & 1541,260377 & $-467,66$ & 2002 & 1333 & 1541,260377 & $-208,26$ \\
\hline 1975 & 1151,4 & 1541,260377 & $-389,86$ & 2003 & 1144 & 1541,260377 & $-397,26$ \\
\hline 1976 & 1886,6 & 1541,260377 & 345,3396 & 2004 & 1516,6 & 1541,260377 & $-24,6604$ \\
\hline 1977 & 1910,5 & 1541,260377 & 369,2396 & 2005 & 1681,3 & 1541,260377 & 140,0396 \\
\hline 1978 & 1566,9 & 1541,260377 & 25,63962 & 2006 & 1445,5 & 1541,260377 & $-95,7604$ \\
\hline 1979 & 1855,6 & 1541,260377 & 314,3396 & 2007 & 1485,4 & 1541,260377 & $-55,8604$ \\
\hline 1980 & 1798,4 & 1541,260377 & 257,1396 & 2008 & 1417,7 & 1541,260377 & $-123,56$ \\
\hline 1981 & 1862,5 & 1541,260377 & 321,2396 & 2009 & 1758 & 1541,260377 & 216,7396 \\
\hline 1982 & 2054,6 & 1541,260377 & 513,3396 & 2010 & 1172,6 & 1541,260377 & $-368,66$ \\
\hline 1983 & 2731,5 & 1541,260377 & 1190,24 & 2011 & 1618,1 & 1541,260377 & 76,83962 \\
\hline 1984 & 1210,9 & 1541,260377 & $-330,36$ & 2012 & 1390,7 & 1541,260377 & $-150,56$ \\
\hline 1985 & 1714,3 & 1541,260377 & 173,0396 & 2013 & 1686,9 & 1541,260377 & 145,6396 \\
\hline 1986 & - & 1541,260377 & - & 2014 & 967,7 & 1541,260377 & $-573,56$ \\
\hline 1987 & - & 1541,260377 & - & 2015 & 1431,7 & 1541,260377 & $-109,56$ \\
\hline 1988 & 1398,7 & 1541,260377 & $-142,56$ & 2016 & 1465,7 & 1541,260377 & $-75,5604$ \\
\hline 1989 & 1397,6 & 1541,260377 & $-143,66$ & 2017 & 1089,2 & 1541,260377 & $-452,06$ \\
\hline
\end{tabular}

Fonte - ANA (2018).

Conforme é possível verificar, parece que os volumes de chuvas anuais acima da média concentram-se nas duas primeiras décadas da série, enquanto que os índices abaixo da média se concentram nas últimas três décadas.

Tal constatação é importante, pois pode sinalizar uma mudança paulatina nas características atmosféricas da área, recobrando um constante monitoramento com o propósito de verificar se está em curso uma possível mudança climática, ou, se entra em cena um período cíclico caracterizado pela diminuição da umidade. 


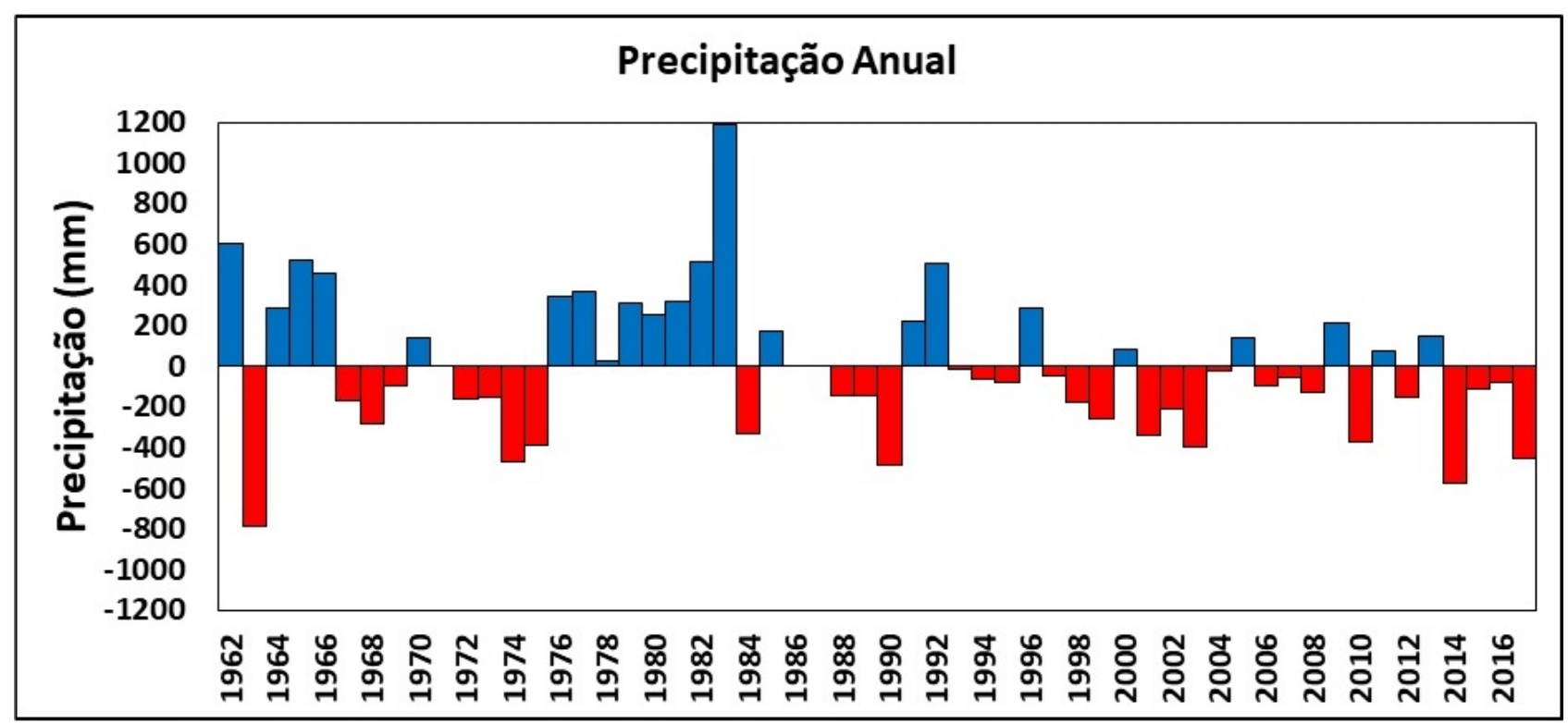

Figura 2 - Variação da Precipitação em Machado/MG em relação a média histórica no período 1962-2017.

Fonte - ANA (2018)

Infelizmente não há dados confiáveis para três anos da série, a saber, 1971, 1986 e 1987, por isso a média foi calculada para os demais 53 anos registrados satisfatoriamente ainda que o período seja composto por 56 anos.

Além da interpretação inicial baseada no tamanho das barras azuis e vermelhas em relação a linha de média estabelecida na Figura 2, a metodologia adotada nessa pesquisa trará, com base nos parâmetros que estabelece, um quadro bem mais detalhado do comportamento da precipitação ao longo da série, destacando a ocorrência das cinco classes que estabelece quanto a umidade anual, a saber, Normal (N), Tendente a Seco (TS), Tendente a Chuvoso (TS), Seco (S), e, Chuvoso (C).

Uma vez que a média do período é de 1.541,26 mm, os anos considerados Normais $(\mathrm{N})$ estarão situados entre 1.310,07 e 1.772,44 mm, enquanto que os anos Tendentes a Secos (TS) estarão compreendidos entre 1.078,88 e 1.310,07 mm, os Tendentes a Chuvosos (TS) entre 1.772,44 e 2.003,63 mm, os Secos (S) em índices inferiores a 1.078,88 mm, e, os Chuvosos com índices superiores a 2.003,63 $\mathrm{mm}$.

Tabela 3 - Frequência das Classes de Umidade na Série Histórica 1962-2017.

\begin{tabular}{cccc}
\hline Classes & Frequência Anual & $\%$ & Colocação \\
\hline C & $5 x$ & $09,43 \%$ & $4^{\mathbf{o}}$ \\
TC & $8 x$ & $15,09 \%$ & $2^{\text {o }}$ \\
N & $29 x$ & $54,71 \%$ & $1^{\text {o }}$ \\
TS & $8 x$ & $15,09 \%$ & $2^{\text {o }}$ \\
S & $3 x$ & $05,66 \%$ & $5^{\text {o }}$ \\
\hline
\end{tabular}


Tabela 4 - Principais Classes e seus Anos Representativos 1962-2017.

PERÍODO
CHUVOSO (1983)

NORMAL (1993)
SECO (1963)

MÉDIA (1962-2017)

\begin{tabular}{lllll}
\hline ANUAL & $2.731,5$ & $1,275,4$ & 752,9 & $1.541,26$ \\
\hline
\end{tabular}

Segundo a Tabela 3 deixa claro, prevalece na área um padrão atmosférico habitual frente a média da série histórica adotada, pois, além da normalidade $(\mathrm{N})$ ser a característica de 54,71\% (29 índices pluviométricos) dos anos que compõe o período considerado, os parâmetros transitórios elencados na classificação como Tendente a Seco (TS) e Tendente a Chuvoso (TC) preenchem quase um terço da série alcançando 30,18\% dos anos (16 índices pluviométricos), restando para os extremos Chuvoso (C) e Seco (S) o percentual de 15,09\% com respectivamente cinco e três anos do total cada (8 índices pluviométricos no total da série histórica).

Atentando para o padrão que acusa uma transição do período úmido das décadas iniciais da série para a diminuição de precipitação registrada nas últimas décadas, uma análise específica desse último hiato de tempo foi feita com base nos dados (Figura 3 e Tabelas 5, 6 e 7) do Instituto Nacional de Meteorologia - INMET por possibilitar o manuseio de outros dados e permitir a constatação ou não desse cenário de diminuição da oferta hídrica.

Tabela 5 - Precipitação anual da Série Histórica (1991-2017).

\begin{tabular}{cccc}
\hline ANOS & TOTAL & MÉDIA (27 anos) & DM \\
\hline 1991 & 1762,6 & 1470,08 & 292,52 \\
1992 & 2051,3 & 1470,08 & 581,22 \\
1993 & 1527,4 & 1470,08 & 57,32 \\
1994 & 1477,1 & 1470,08 & 7,02 \\
1995 & 1465,7 & 1470,08 & $-4,38$ \\
1996 & 1831,3 & 1470,08 & 361,22 \\
1997 & 1495,5 & 1470,08 & 25,42 \\
1998 & 1366,3 & 1470,08 & $-103,78$ \\
1999 & 1280,8 & 1470,08 & $-189,28$ \\
2000 & 1629,7 & 1470,08 & 159,62 \\
2001 & 1200,4 & 1470,08 & $-269,68$ \\
2002 & 1333 & 1470,08 & $-137,08$ \\
2003 & 1144 & 1470,08 & $-326,08$ \\
2004 & 1516,6 & 1470,08 & 46,52 \\
2005 & 1681,3 & 1470,08 & 211,22 \\
2006 & 1445,5 & 1470,08 & $-24,58$ \\
2007 & 1485,4 & 1470,08 & 15,32 \\
2008 & 1417,7 & 1470,08 & $-52,38$ \\
2009 & 1758 & 1470,08 & 287,92 \\
2010 & 1172,6 & 1470,08 & $-297,48$ \\
2011 & 1618,1 & 1470,08 & 148,02 \\
2012 & 1390,7 & 1470,08 & $-79,38$ \\
2013 & 1686,9 & 1470,08 & 216,82 \\
2014 & 967,7 & 1470,08 & $-502,38$ \\
2015 & 1431,7 & 1470,08 & $-38,38$ \\
2016 & 1465,7 & 1470,08 & $-4,38$ \\
2017 & 1089,2 & 1470,08 & $-380,88$ \\
\hline & & $50 n t e$ & \\
\hline
\end{tabular}

Fonte - INMET (2018). 


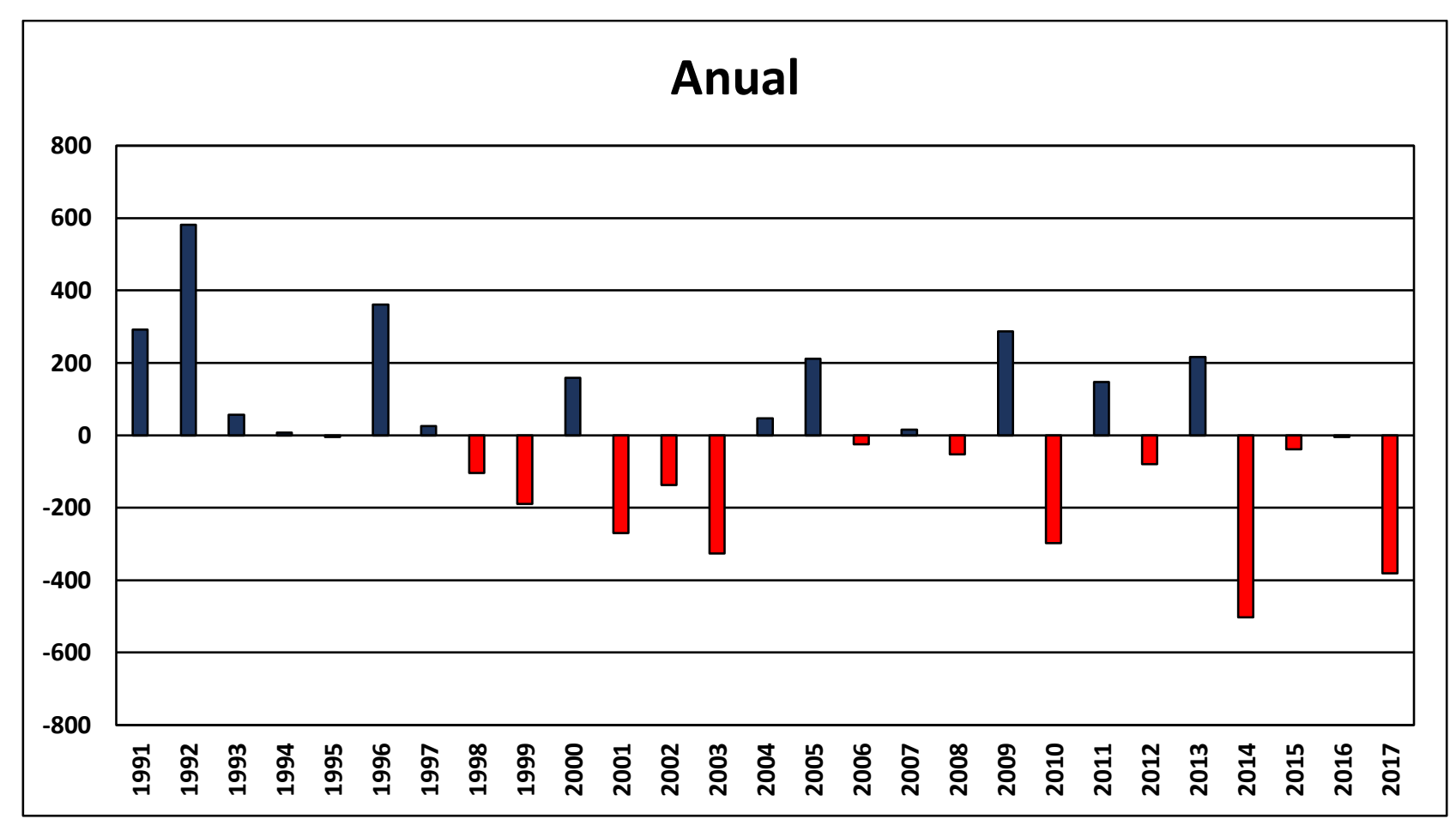

Figura 3 - Precipitação anual da série em relação à média (1991-2017). Fonte - INMET (2018).

É preocupante o fato de que os anos úmidos estejam concentrados no início desta série 1992 - 1996, ao passo que os anos secos estejam prevalecendo a partir do segundo terço dos anos avaliados com predomínio entre 1998 - 2003 e 2014 - 2017.

Mesmo que exista uma ligeira diferença para com os dados fornecidos pela ANA (2018), é perceptível que prevalece nos últimos anos um cenário de diminuição do índice de precipitação anual, algo que pode ser comprometedor se estiver acompanhado por aguaceiros intensos isolados ao longo do ano, sobretudo por somar à diminuição da oferta hídrica os longos períodos de estiagem que ficam estabelecidos quando a precipitação se torna mal distribuída - algo que convém ser analisado comparando os semestre chuvosos e secos característicos dos domínios monçônicos tropicais.

No que tange a aplicação da metodologia adotada nessa pesquisa, obtém-se o resultado expresso na Tabela 6 com base nos parâmetros que preconizam a ocorrência das cinco classes quanto a umidade anual, a saber, Normal $(\mathrm{N})$ com índices situados entre 1.249,57 e 1.690,6 mm, Tendente a Seco (TS) com precipitação entre 1.029,05 e 1.249,59 mm, Tendente a Chuvoso (TS) alcançando entre 1.690,6 e 1.911,1 mm, Seco (S) com chuvas baixo de 1.029,05 mm, e, Chuvoso (C) com pluviometria acima de 1.911,1 mm. Para essa série a média observada é 1.470,08 mm, considerandose o hiato de vinte e sete anos de registros pluviométricos sem perda. Obviamente, como os pontos de coleta da ANA não são os mesmos do INMET, fica esclarecida a pequena diferença que possuem. 
Tabela 6 - Frequência das Classes de Umidade na Série Histórica 1991-2017.

\begin{tabular}{cccc}
\hline Classes & Frequência Anual & \% & Colocação \\
\hline C & $1 \mathrm{x}$ & $03,70 \%$ & $4^{\text {o }}$ \\
TC & $3 \mathrm{x}$ & $11,11 \%$ & $2^{\text {o }}$ \\
N & $19 \mathrm{x}$ & $70,37 \%$ & $1^{\text {o }}$ \\
TS & $3 \mathrm{x}$ & $11,11 \%$ & $2^{\mathrm{o}}$ \\
S & $1 \mathrm{x}$ & $03,70 \%$ & $4^{\text {o }}$ \\
\hline
\end{tabular}

Tabela 7 - Principais Classes e seus Anos Representativos.

\begin{tabular}{ccccc}
\hline PERÍODO & $\begin{array}{c}\text { CHUVOSO } \\
(\mathbf{1 9 9 2})\end{array}$ & $\begin{array}{c}\text { NORMAL } \\
(\mathbf{1 9 9 5} ; \mathbf{2 0 1 6})\end{array}$ & $\begin{array}{c}\text { SECO } \\
\mathbf{( 2 0 1 4 )}\end{array}$ & $\begin{array}{c}\text { MÉDIA } \\
(\mathbf{1 9 9 1 - 2 0 1 7 )}\end{array}$ \\
\hline ANUAL & $2.051,3$ & $1.465,7$ & 967,7 & $1.470,08$
\end{tabular}

Segundo a Tabela 6 deixa claro, prevalece na área mais uma vez um padrão atmosférico de normalidade frente a média da série histórica adotada, pois, os anos que apresentaram índice pluviométrico situado dentro do intervalo admitido para os Anos Normais alcançam 70,37\% do total da série - dezenove em vinte e sete, enquanto que os períodos de transição entre a normalidade e os extremos - Anos Tendente a Seco ou Tendente a Chuvoso - recobrem 22,22\% da série ou seis anos, relegando os momentos extremos - Ano Seco ou Ano Chuvoso - a meros 7,4\% ou apenas dois anos.

Assim, diante do que foi possível observar nos dados das Tabelas 2, 3, 5 e 6, assim como nas Figuras 2 e 3, a área analisada de Machado/MG desfruta de um padrão atmosférico pautado pela habitualidade de sua precipitação, tendo como esporádicas as situações extremas que caracterizam momentos de seca e aguaceiro para os parâmetros do tipo climático que nela se manifestam.

No entanto, ainda que essa normalidade prevaleça, o comportamento da precipitação na segunda metade das séries históricas sinaliza uma pequena, mas contínua redução no volume dos índices pluviométricos, evidenciando o retorno de um ciclo já inserido no padrão atmosférico da área, ou, o advento de uma nova conjuntura oriunda de uma possível mudança climática em curso no planeta nos últimos anos como defendem alguns estudiosos.

Tal percepção advém da frequência com que os índices abaixo da média se manifestam nas duas séries, sinalizando um predomínio a partir da segunda metade da década de noventa que se estende até o último registro. É verdade que seu distanciamento da média é menor que aquele apresentado pelos anos úmidos ocorridos no início das séries ou na sua primeira parte; todavia, ainda assim, essa tendência deve ser considerada em razão do aumento que passa a ocorrer ano a ano na demanda por água.

Esse binômio - diminuição da oferta hídrica ; aumento no consumo - é extremamente preocupante, pois ocorre no momento em que o aumento do consumo de água se dá tanto pelo 
aumento da população como pelas práticas decorrentes do nível de consumismo que se estabelece em todas as partes do planeta, inclusive na área de estudo.

Em razão disto, a análise que seguiu sobre o comportamento da precipitação se ocupou com os períodos distintos que se estabelecem ao longo do ano, o semestre chuvoso (outubro a março), e, o semestre seco (abril a setembro), buscando verificar se a tendência de diminuição da precipitação é acompanhada pela perversa concentração das chuvas em determinados momentos do ano, agravando ainda mais o cenário devido à ausência de ações e estratégias ocupadas com o armazenamento do excedente momentâneo que se perde por escoamento superficial e evaporação.

Essa avaliação foi feita com os dados das duas séries já apresentadas; aquela fornecida pela ANA (2018) abrangendo os anos de 1962 a 2017 (Figuras 4 e 5, e, Tabelas 8, 9 e 11), e, a fornecida pelo INMET (2018) perfazendo os anos de 1991 a 2017 (Figuras 6 e 7, e, Tabelas 13 e 14) com seus respectivos dados obtidos de suas estações meteorológicas em Machado/MG.

Infelizmente os dados referentes aos anos de 1971, 1986 e 1987 não estão completos e por isso não foi possível contabilizá-los.

Uma vez que a média para os semestres chuvosos é de $1.188,71 \mathrm{~mm}$ e para os semestres secos é de 265,95 mm, já é possível verificar nesses dados iniciais a distância que existe entre os patamares de precipitação recebidos em cada um desses semestres, pois, o volume médio registrado entre abril e setembro é cerca de quatro vezes menor que aquele recebido entre os meses de outubro a março. Aliás, não fossem os índices apresentados nos anos de 1970, 1976, 1977, 1979, 1983, 1992 e 2009, não mais que sete anos de toda a série, e a diferença seria tranquilamente de cinco vezes, podendo inclusive chegar a cinco vezes e meia não fosse os registros ocorridos em 1970, 1985 e 1987 nos semestres chuvosos da série.

Um outro agravante observado nas Figuras 4 e 5 diz respeito ao volume de precipitação ocorrido a partir da década de 1990, posto que fica evidente o decréscimo paulatino dos índices pertinentes aos semestres secos, mesmo que o mesmo não ocorra de forma tão perceptível nos semestres chuvosos, permitindo, por conseguinte, a inferência de que a possível diminuição dos índices pluviométricos na área estejam atrelada a queda das chuvas no momento de estresse hídrico compreendido entre os meses de abril a setembro, agravando a situação e a demanda por água nesse período do ano. 
Tabela 8 - Precipitação dos Semestres Chuvoso e Seco da série 1962-2017.

\begin{tabular}{|c|c|c|c|c|c|}
\hline ANOS & $\begin{array}{l}\text { SEMESTRE } \\
\text { CHUVOSO }\end{array}$ & $\begin{array}{c}\text { SEMESTRE } \\
\text { SECO }\end{array}$ & ANOS & $\begin{array}{c}\text { SEMESTRE } \\
\text { CHUVOSO }\end{array}$ & $\begin{array}{c}\text { SEMESTRE } \\
\text { SECO }\end{array}$ \\
\hline 1962 & 1479 & 258,4 & 1990 & 1404,2 & 311 \\
\hline 1963 & 1066,4 & 26,5 & 1991 & 1462,1 & 217,2 \\
\hline 1964 & 1690,7 & 299,3 & 1992 & 1409,2 & 509,4 \\
\hline 1965 & 1562,1 & 367,4 & 1993 & 1107,3 & 316,2 \\
\hline 1966 & 1579,7 & 196,1 & 1994 & 1308,4 & 194,4 \\
\hline 1967 & 1019 & 161,3 & 1995 & 1145,6 & 196,5 \\
\hline 1968 & 1275,9 & 156,3 & 1996 & 1511,9 & 374,6 \\
\hline 1969 & 1445,6 & 126,4 & 1997 & 1006,8 & 377,7 \\
\hline 1970 & 475,7 & 470,3 & 1998 & 1366,4 & 238 \\
\hline 1971 & - & - & 1999 & 1230,9 & 202,5 \\
\hline 1972 & 1072 & 237 & 2000 & 925,1 & 255,9 \\
\hline 1973 & 1104 & 238,8 & 2001 & 1259,4 & 177,4 \\
\hline 1974 & 856,8 & 208,4 & 2002 & 1000,9 & 130,1 \\
\hline 1975 & 1061,6 & 200,2 & 2003 & 1152,7 & 158,7 \\
\hline 1976 & 1269,4 & 569,6 & 2004 & 1453,5 & 291,5 \\
\hline 1977 & 1246,1 & 745,7 & 2005 & 1080,8 & 371,4 \\
\hline 1978 & 1382,1 & 211,3 & 2006 & 1455,5 & 93,4 \\
\hline 1979 & 1397,2 & 473,5 & 2007 & 1076,8 & 235,3 \\
\hline 1980 & 1466,8 & 409,6 & 2008 & 1208,9 & 329,6 \\
\hline 1981 & 2014,4 & 179,2 & 2009 & 1029,3 & 499,4 \\
\hline 1982 & 1777,2 & 300 & 2010 & 1369,5 & 179,8 \\
\hline 1983 & 1323,9 & 716 & 2011 & 1101 & 158,8 \\
\hline 1984 & 1468,9 & 300,5 & 2012 & 1488,3 & 296,2 \\
\hline 1985 & 532,6 & 230 & 2013 & 795,2 & 262 \\
\hline 1986 & - & - & 2014 & 1135,2 & 217,3 \\
\hline 1987 & 666,6 & - & 2015 & 1270,8 & 249,4 \\
\hline 1988 & 1024,9 & 248,5 & 2016 & 870,8 & 186,7 \\
\hline 1989 & 897,2 & 310,4 & 2017 & - & 222,3 \\
\hline
\end{tabular}

Fonte - ANA (2018). 


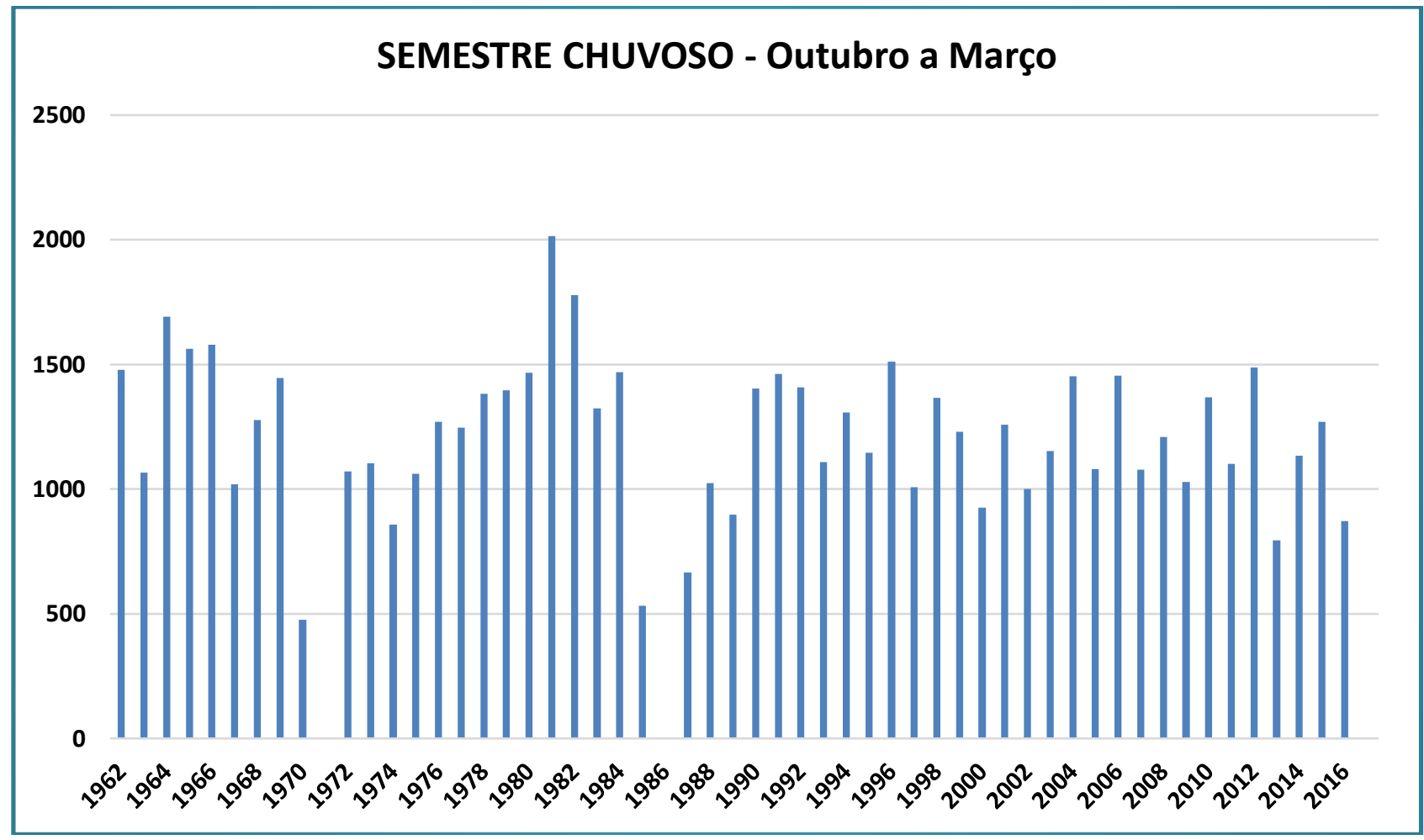

Figura 4 - Precipitação dos Semestres Chuvosos de 1962 a 2017. Fonte - ANA (2018).

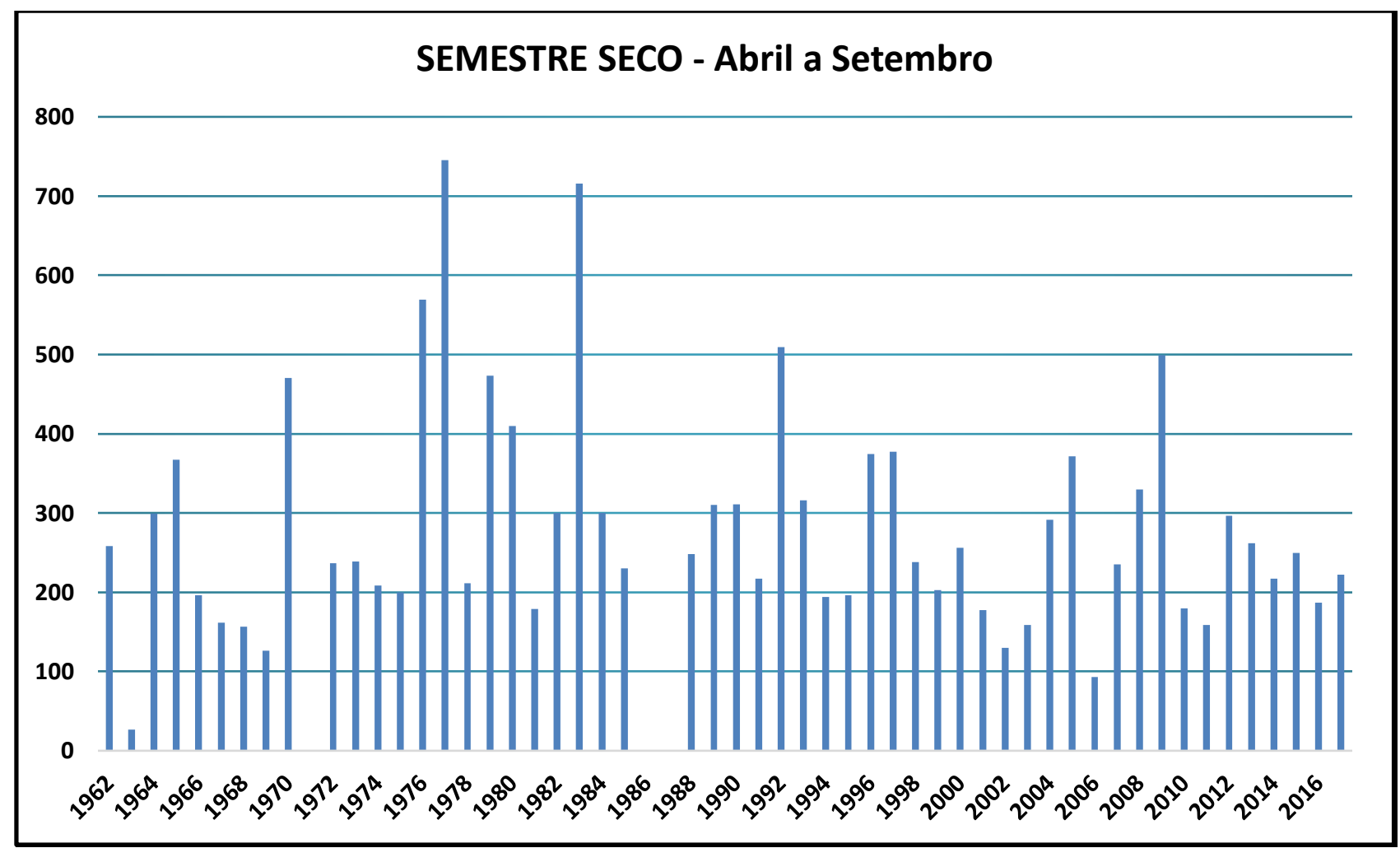

Figura 5 - Precipitação dos Semestres Secos de 1962 a 2017

Fonte - ANA (2018) 
Tabela 9 - Frequência das Classes de Umidade para os Semestres Chuvosos na Série Histórica 1962-2017.

\begin{tabular}{cccc}
\hline Classes & Frequência Anual & $\%$ & Colocação \\
\hline C & $5 \mathrm{x}$ & $09,43 \%$ & $4^{\mathbf{o}}$ \\
TC & $14 \mathrm{x}$ & $26,41 \%$ & $2^{\text {o }}$ \\
N & $24 \mathrm{x}$ & $45,28 \%$ & $1^{\text {o }}$ \\
TS & $6 \mathrm{x}$ & $11,32 \%$ & $3^{\text {o }}$ \\
S & $4 \mathrm{x}$ & $07,54 \%$ & $5^{\mathbf{o}}$ \\
\hline
\end{tabular}

Tabela 10 - Principais Classes e seus Anos Representativos para os Semestres Chuvosos na Série Histórica 1962-2017.

PERÍODO CHUVOSO (1981) NORMAL (2003) SECO (1970) MÉDIA (1962-2017)

\begin{tabular}{|c|c|c|c|}
\hline ANUAL & $2.014,4$ & $1.152,7$ & 475,7 \\
\hline
\end{tabular}

Com relação aos dados específicos do Semestre Chuvoso - outubro a março, pode-se constatar que o quadro de habitualidade permanece, ainda que nos últimos vinte anos uma ligeira diminuição no volume de precipitação é registrada. Não obstante a isto, o quadro geral mantém-se dentro da habitualidade esperada, demonstrando que os processos responsáveis pela precipitação, ocorrida de outubro a março, não sofreram mudanças bruscas ao ponto de comprometer a oferta de água para a região, sobretudo se essa pequena alteração verificada nas últimas duas décadas e meia da série manifestarem algum retorno cíclico muito bem acomodado no padrão histórico da atmosfera.

Em relação aos dados pertinentes ao Semestre Seco - abril a setembro, verifica-se que a possível habitualidade verificada nos demais meses do ano pode estar com os dias contados, antecedendo uma nova configuração atmosférica que resulte em índices mais baixos que aqueles visualizados do início da série até o final da década de oitenta.

É verdade que a habitualidade histórica dessa conjuntura atmosférica pode contemplar hiatos onde uma ligeira queda na precipitação nos meses mais chuvosos do ano - outubro a março - seja acompanhada por uma redução mais pronunciada e perceptível nos meses mais secos - abril a setembro, agravando a oferta de recurso hídrico, no entanto, ainda assim, orienta os planejadores e administradores públicos a desenvolverem estratégias de intervenção que contemple a diminuição da precipitação nessa época do ano.

Atestando a volatilidade desse período e a oscilação maior das variáveis que atuam em sua conjuntura atmosférica, a Tabela 11 apresenta o predomínio das classes ao longo da série histórica.

Nos semestres secos não há um destacado predomínio da habitualidade, pois, dos cinquenta e três índices considerados, um pouco mais que a metade - trinta anos (56,6\%) - estão orbitando ao redor da média, ao passo que vinte e três situam-se nos extremos, alcançando $43,4 \%$ de todo o período. Desta forma, fica notório o caráter inconstante desses meses do ano que alterna precipitação da ordem de 745,7 mm (1977) com outras quase imperceptíveis de 26,5 mm (1963). 
Tabela 11 - Frequência das Classes de Umidade para os Semestres Secos na Série Histórica 1962-2017.

\begin{tabular}{cccc}
\hline Classes & Frequência Anual & $\%$ & Colocação \\
\hline C & $12 \mathrm{x}$ & $22,64 \%$ & $2^{\mathbf{o}}$ \\
TC & $4 \mathrm{x}$ & $07,54 \%$ & $5^{\mathbf{o}}$ \\
N & $15 \mathrm{x}$ & $28,30 \%$ & $1^{\mathrm{o}}$ \\
TS & $11 \mathrm{x}$ & $20,75 \%$ & $3^{\text {o }}$ \\
S & $11 \mathrm{x}$ & $20,75 \%$ & $3^{\text {o }}$ \\
\hline
\end{tabular}

Tabela 12 - Principais Classes e seus Anos Representativos para os Semestres Secos na Série Histórica 1962-2017.

\begin{tabular}{c|cccc}
\hline PERÍODO & CHUVOSO (1977) & NORMAL (1962) & SECO (1963) & MÉDIA (1962-2017) \\
\hline ANUAL & 745,7 & 258,4 & 26,5 & 265,95 \\
\hline
\end{tabular}

Como a situação demonstrada nas últimas duas décadas da série é a mais preocupante - caso não constitua ciclo inserido no padrão atmosférico da área, mais uma vez convém avaliar os dados disponibilizados pelo INMET (2018) na série 1991-2017, dividindo o ano em suas quatro estações para salientar as condições que prevalecem num curto espaço de tempo.

Segundo é possível verificar nas Figuras 6 e 7, mais uma vez há um comportamento diferente entre os semestres chuvosos e secos.

Ao que tudo indica as séries apresentam índices próximos, pois a média da fornecida pela ANA (1962-2017) é apenas 2,09 mm menor para Semestre Chuvoso que aquela do período catalogado pelo INMET (1991-2017), enquanto que no Semestre Seco é 8,85 mm maior.

Prosseguindo com as considerações sobre o comportamento da precipitação ao longo da série, é possível observar no que tange aos semestres chuvosos apresentados na Figura 7 que existe no primeiro terço do período um predomínio dos anos com umidade acima da média - seis anos com umidade acima da média contra três anos com índices abaixo da média; no entanto, a situação sofre inverso no último terço, confirmando a transição já verificada na série anterior.

Em relação as informações contidas na Figura 7, cumpre destacar que os anos com índices inferiores à média predominam frente aqueles que possuem precipitação acima, confirmando mais uma vez a condição desfavorável que prevalece nessa época do ano para o uso e consumo de água na área de estudo. Segundo é possível contabilizar, para cada ano com maior umidade na série, outros dois concorrem com registros inferiores.

Infelizmente, nessa época do ano a carência das chuvas provocam um aumento no consumo de água, agravando o quadro instalado na área que passa a ressentir-se da oferta desse insumo fundamental à vida e ao desenvolvimento das atividades antrópicas. 


\section{Semestre Chuvoso}

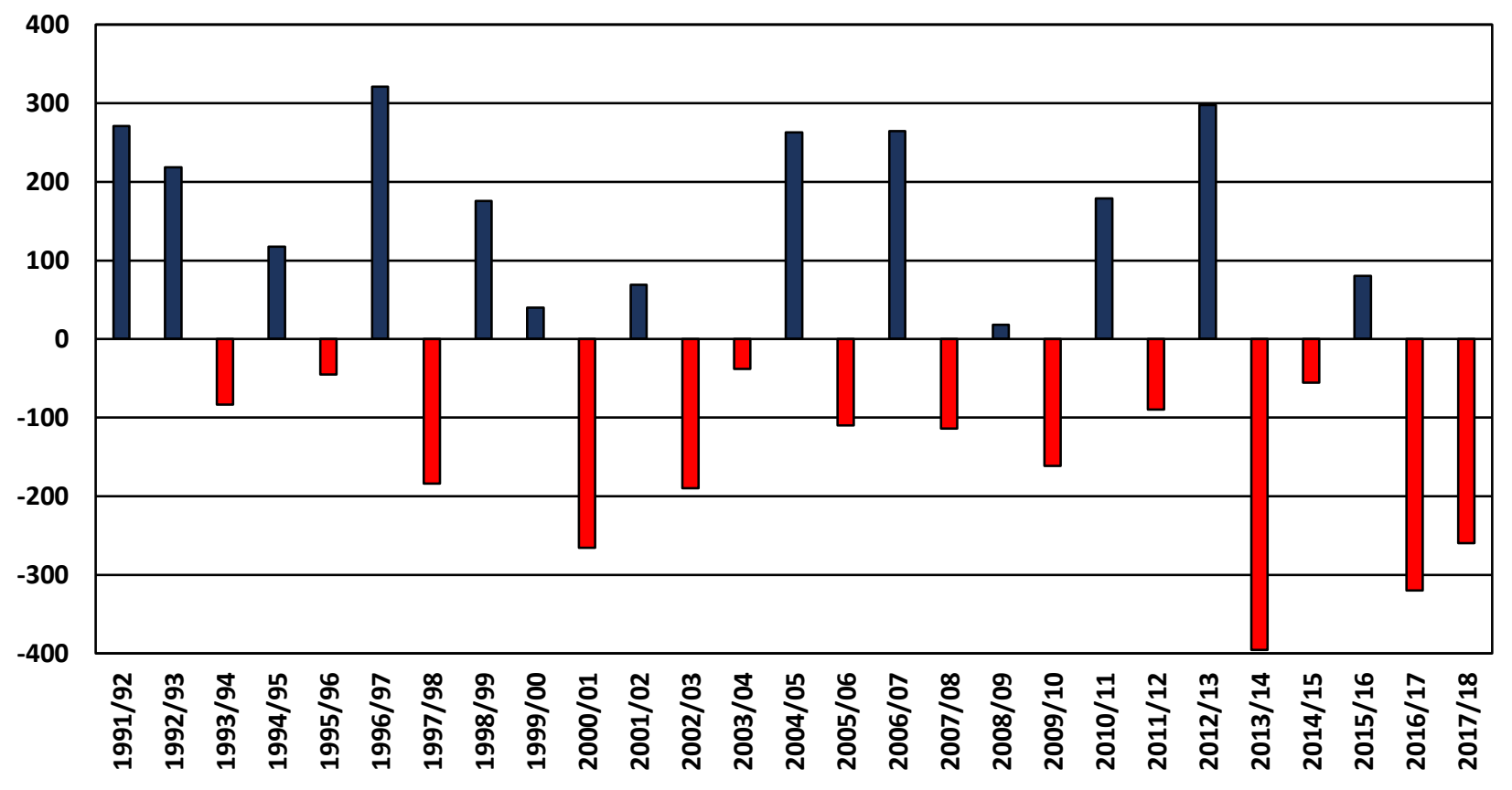

Figura 6 - Semestres Chuvosos da série histórica 1991-2017. Fonte: INMET (2018).

Tabela 13 - Precipitação dos Semestres Chuvoso e Seco da série 1991-2017.

\begin{tabular}{cccccc}
\hline Ano & $\begin{array}{c}\text { Semestre } \\
\text { Chuvoso }\end{array}$ & $\begin{array}{c}\text { Semestre } \\
\text { Seco }\end{array}$ & Ano & $\begin{array}{c}\text { Semestre } \\
\text { Chuvoso }\end{array}$ & $\begin{array}{c}\text { Semestre } \\
\text { Seco }\end{array}$ \\
\hline 1991 & 1462,1 & 217,2 & 2005 & 1080,8 & 371,4 \\
1992 & 1409,2 & 509,4 & 2006 & 1455,5 & 93,4 \\
1993 & 1107,3 & 316,2 & 2007 & 1076,8 & 235,3 \\
1994 & 1308,4 & 194,4 & 2008 & 1208,9 & 329,6 \\
1995 & 1145,6 & 196,5 & 2009 & 1029,3 & 499,4 \\
1996 & 1511,9 & 374,6 & 2010 & 1369,5 & 179,8 \\
1997 & 1006,8 & 377,7 & 2011 & 1101 & 158,8 \\
1998 & 1366,4 & 238 & 2012 & 1488,3 & 296,2 \\
1999 & 1230,9 & 202,5 & 2013 & 795,2 & 262 \\
2000 & 925,1 & 255,9 & 2014 & 1135,2 & 217,3 \\
2001 & 1259,4 & 177,4 & 2015 & 1270,8 & 249,4 \\
2002 & 1000,9 & 130,1 & 2016 & 870,8 & 186,7 \\
2003 & 1152,7 & 158,7 & 2017 & 931 & 222,3 \\
2004 & 1453,5 & 291,5 & & &
\end{tabular}

Fonte - INMET (2018). 


\section{Semestre Seco}

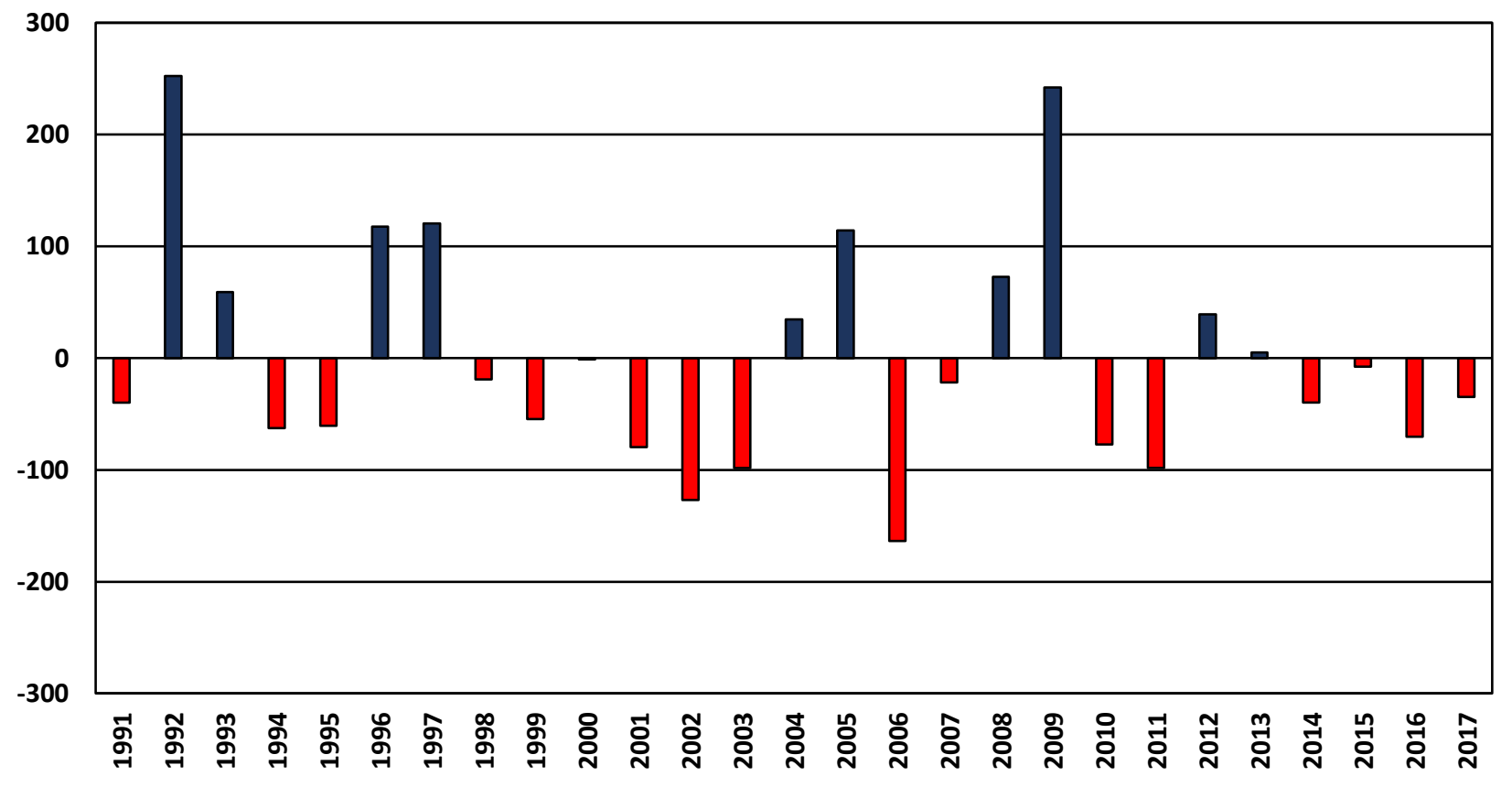

Figura 7 - Semestres Secos da série histórica 1991-2017. Fonte - INMET (2018).

Tabela 14 - Frequência das Classes de Umidade para os Semestres Chuvosos e Secos na Série Histórica 1991-2017.

\begin{tabular}{ccccccc}
\hline Classes & $\begin{array}{c}\text { Semestre } \\
\text { Chuvoso }\end{array}$ & $\%$ & Frequência & $\begin{array}{c}\text { Semestre } \\
\text { Seco }\end{array}$ & $\%$ & Frequência \\
\hline $\mathrm{C}$ & - & - & - & $5 \mathrm{x}$ & $18,51 \%$ & $3^{\mathrm{o}}$ \\
$\mathrm{TC}$ & $7 \mathrm{x}$ & $25,92 \%$ & $2^{\mathrm{o}}$ & $2 \mathrm{x}$ & $7,40 \%$ & $5^{\mathrm{o}}$ \\
$\mathrm{N}$ & $14 \mathrm{x}$ & $51,83 \%$ & $1^{\mathrm{o}}$ & $10 \mathrm{x}$ & $37,02 \%$ & $1^{\mathrm{o}}$ \\
$\mathrm{TS}$ & $5 \mathrm{x}$ & $18,51 \%$ & $3^{\mathrm{o}}$ & $6 \mathrm{x}$ & $22,22 \%$ & $2^{\mathrm{o}}$ \\
$\mathrm{S}$ & $1 \mathrm{x}$ & $3,7 \%$ & $4^{\mathrm{o}}$ & $4 \mathrm{x}$ & $14,81 \%$ & $4^{\mathrm{o}}$ \\
\hline
\end{tabular}

Tabela 15 - Principais Classes e Anos Representativos para os Semestres Chuvosos e Secos no período 1991-2017.

\begin{tabular}{|c|c|c|c|c|}
\hline PERÍODO & $\begin{array}{c}\text { CHUVOSO } \\
(1996-97)\end{array}$ & $\begin{array}{l}\text { NORMAL } \\
(2000)\end{array}$ & $\begin{array}{l}\text { SECO } \\
(2014) \\
\end{array}$ & $\begin{array}{c}\text { MÉDIA } \\
(1991 / 92-2017 / 18)\end{array}$ \\
\hline $\begin{array}{l}\text { SEMESTRE } \\
\text { CHUVOSO }\end{array}$ & $1.511,9 \mathrm{~mm}$ & $1.208,9 \mathrm{~mm}$ & $795,2 \mathrm{~mm}$ & $1.190,8 \mathrm{~mm}$ \\
\hline PERÍODO & $\begin{array}{c}\text { CHUVOSO } \\
(1996-97)\end{array}$ & $\begin{array}{c}\text { NORMAL } \\
(2000)\end{array}$ & $\begin{array}{l}\text { SECO } \\
(2014) \\
\end{array}$ & $\begin{array}{c}\text { MÉDIA } \\
(1991-2017)\end{array}$ \\
\hline $\begin{array}{l}\text { SEMESTRE } \\
\text { SECO }\end{array}$ & $509,4 \mathrm{~mm}$ & $255,9 \mathrm{~mm}$ & $93,4 \mathrm{~mm}$ & $257,1 \mathrm{~mm}$ \\
\hline
\end{tabular}


Conforme as Tabelas 14 e 15 demonstram mais uma vez, a principal diferença entre os Semestres encontra-se na habitualidade e a ponderação média.

A habitualidade dos semestres chuvosos é tamanha que garante quase a totalidade da série nas classes Normal (N), Tendente a Seco (TS) ou Tendente a Chuvoso (TC), relegando ao extremo um único ano situado na classe Seco (S). Por seu turno, nos semestres secos anota-se um terço da série na condição extrema com cinco anos chuvosos em relação à média e outros quatro secos, asseverando que as oscilações são mais comuns nesse período.

À luz dessas constatações, a pesquisa seguiu adiante, debruçando-se especificamente sobre os trimestres anuais que se dividem nas quatro estações do ano com o intuito de verificar se o quadro de escassez se torna agudo em alguma delas e como se comporta a habitualidade frente a média que é estabelecida e ao padrão de distribuição anual da precipitação na área.

Como o Semestre Chuvoso compreende a Primavera e o Verão, essas duas estações estiveram associadas nos comentários que se seguem, assim como estiveram relacionados Inverno e Outono por compreenderem o hiato ocupado pelo Semestre Seco ao longo do ano.

Como os dados disponibilizados pela ANA (2018) (Tabela 16 e Figuras 8, 9, 10 e 11) abrangeram um hiato temporal maior - seguindo desde a década de sessenta até a segunda década do novo milênio; foram analisados antes daqueles disponibilizados pelo INMET (2018) (Tabela 20). Em ambas as séries o conjunto de meses e estações foi organizado da seguinte maneira; a Primavera abrangeu outubro, novembro e dezembro, o Verão abrangeu janeiro, fevereiro e março, o Outono compreendeu abril, maio e junho, e o Inverno foi composto pelos dados de junho, julho e agosto.

A sequência adotada de análise seguiu o propósito anterior de investigar possíveis tendências na série maior (1962-2017) para depois verifica-las na série menor (1991-2017) que abrange justamente a contemporaneidade dos últimos anos mais suscetíveis às mudanças climáticas.

Segundo foi possível observar na Tabela 16 e Figura 8, os três meses de verão responderam por cerca de 49,22\% da precipitação anual. Graças aos índices verificados nos anos de 2013 e 2016, os últimos quatro anos da série situaram-se relativamente abaixo do padrão, todavia, se comparado com 1970 e 1985, identificam-se elementos para apostar numa situação pontual que será diluída na normalidade dos próximos verões. 
Tabela 16 - Precipitação nas Estações do Ano na série histórica 1962-2917.

\begin{tabular}{|c|c|c|c|c|}
\hline Ano & Verão & Primavera & Outono & Inverno \\
\hline 1962 & 1001,2 & 504,3 & 282,6 & 55,1 \\
\hline 1963 & 847,8 & 171,3 & 110,6 & 10,2 \\
\hline 1964 & 1030,7 & 476,1 & 226,6 & 78,1 \\
\hline 1965 & 884,8 & 451,2 & 426,6 & 116 \\
\hline 1966 & 957,8 & 473,5 & 407,2 & 13,6 \\
\hline 1967 & 648,6 & 382,2 & 247,1 & 58,1 \\
\hline 1968 & 788,3 & 396,6 & 103,3 & 63,6 \\
\hline 1969 & 782,5 & 530 & 199 & 41,9 \\
\hline 1970 & 85,5 & 525,4 & 285,5 & 193,3 \\
\hline 1971 & 508,5 & - & - & - \\
\hline 1972 & 577 & 400,4 & 175,2 & 97 \\
\hline 1973 & 676 & 261 & 299,2 & 38,6 \\
\hline 1974 & 607,6 & 170,2 & 323,4 & 96,8 \\
\hline 1975 & 448,2 & 432,4 & 223,4 & 8 \\
\hline 1976 & 574,4 & 603,8 & 387,8 & 273 \\
\hline 1977 & 699,3 & 513,8 & 764,3 & 55,4 \\
\hline 1978 & 751,8 & 431,9 & 311,7 & 74,6 \\
\hline 1979 & 948,8 & 513,3 & 329,8 & 200,8 \\
\hline 1980 & 937,5 & 315 & 351,2 & 98,2 \\
\hline 1981 & 1030,3 & 558,9 & 341,5 & 90,6 \\
\hline 1982 & 1028,6 & 329,9 & 551 & 162,3 \\
\hline 1983 & 788,3 & 817,7 & 671,8 & 149,3 \\
\hline 1984 & 935,2 & 331,5 & 201 & 54,1 \\
\hline 1985 & 323,3 & 278,5 & 459,3 & 7,5 \\
\hline 1986 & - & - & - & - \\
\hline 1987 & 539,6 & - & - & - \\
\hline 1988 & 567 & 361,6 & 294,5 & 30 \\
\hline 1989 & 546,1 & 338,6 & 247,9 & 101,7 \\
\hline 1990 & 730 & 349,5 & 252,7 & 89,4 \\
\hline 1991 & 1034,7 & 291,7 & 558,6 & 38,5 \\
\hline 1992 & 887,5 & 544,8 & 433,9 & 76,4 \\
\hline 1993 & 568,2 & 359,3 & 293,9 & 46,7 \\
\hline 1994 & 904,6 & 284,5 & 457,8 & 38 \\
\hline 1995 & 643,6 & 390,5 & 242 & 38,9 \\
\hline 1996 & 812,1 & 700,4 & 317,3 & 38,7 \\
\hline 1997 & 602,5 & 373,3 & 348,4 & 122,2 \\
\hline 1998 & 947,4 & 341,4 & 254,8 & 50,2 \\
\hline 1999 & 927,3 & 173,6 & 203,7 & 47,3 \\
\hline 2000 & 474,4 & 411,2 & 236 & 73,5 \\
\hline 2001 & 714,5 & 432,3 & 259,7 & 29,9 \\
\hline 2002 & 574,9 & 362,4 & 231 & 24,7 \\
\hline 2003 & 838,8 & 248,5 & 236,3 & 31,5 \\
\hline 2004 & 857 & 341,8 & 278,3 & 61,8 \\
\hline 2005 & 685,1 & 299,4 & 436 & 66,9 \\
\hline 2006 & 1067,4 & 355,9 & 268,1 & 23,4 \\
\hline 2007 & 515,2 & 332,2 & 228 & 78,6 \\
\hline 2008 & 819,6 & 366,3 & 418,9 & 57,7 \\
\hline 2009 & 699,9 & 299,3 & 353,4 & 139,8 \\
\hline 2010 & 837,2 & 291 & 249,6 & 36,8 \\
\hline 2011 & 667,6 & 323,2 & 408,2 & 33,1 \\
\hline 2012 & 1049,6 & 313,5 & 220,4 & 118,2 \\
\hline 2013 & 304,1 & 422,8 & 311,6 & 81,2 \\
\hline 2014 & 640,3 & 275,9 & 258,8 & 49 \\
\hline 2015 & 758,4 & 394,4 & 340,9 & 46,7 \\
\hline 2016 & 319,2 & 473,5 & 303,8 & 104,5 \\
\hline 2017 & - & 362,7 & 230,6 & 31,6 \\
\hline
\end{tabular}

Fonte - ANA (2018). 


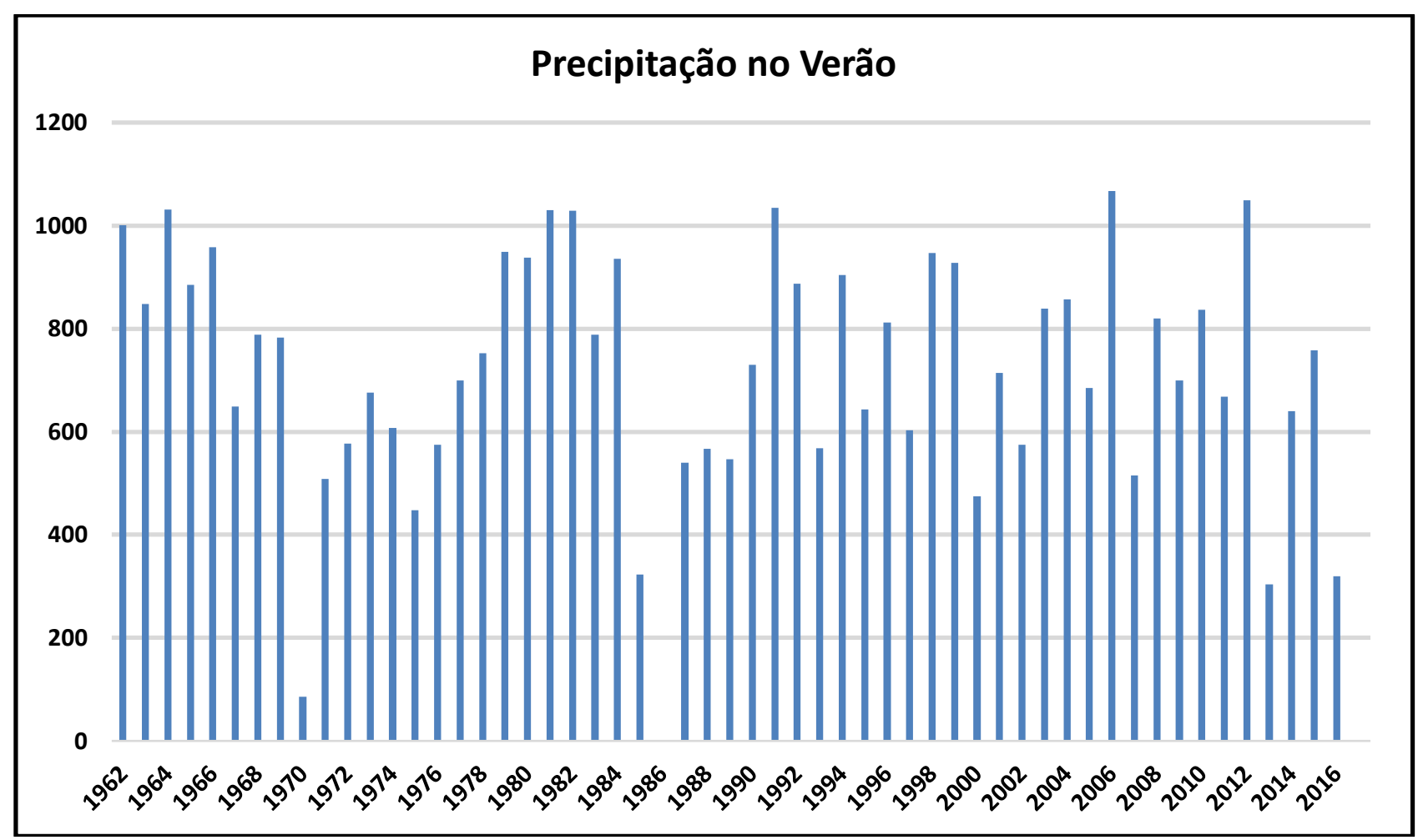

Figura 8 - Precipitação de verão (trimestre) da série histórica 1962-2017.

Fonte - ANA (2018).

Com relação a Primavera, percebeu-se com base na Tabela 16 e Figura 9 que se torna perceptível uma ligeira diminuição na precipitação a partir do final da década de oitenta. Essa informação é importante pois anuncia que possivelmente o período úmido do ano esteja diminuindo em sua extensão temporal, tornando-se menos difuso e mais concentrado, prejudicando com isso o desenvolvimento das ações antrópicas na área e a oferta do recurso hídrico caso haja um aumento em sua demanda.

Também evidencia pontualmente uma certa compensação do desempenho da precipitação no Verão, cooperando com o volume geral ainda que mantendo a tendência estabelecida. Isso fica notório nos últimos anos da série onde os índices de 2013 e 2016 são maiores que os próximos.

Segundo a Tabela 17 demonstra, o semestre chuvoso da série está harmonioso, pois a primavera e o verão possuem uma distribuição geral da frequência de classes igual. É verdade que o número de trimestres inseridos em cada uma das classes é diferente, entretanto, no que tange a ordem de grandeza entre elas, há uma similaridade que comprova a maior habitualidade, assegurando que as mudanças, se, de fato, estiverem em curso, afetam muito mais os meses do semestre seco.

Obviamente essa leitura acerca dos semestres secos pode estar equivocada naquilo que diz respeito aos trimestres, por isso, para assegurar uma melhor compreensão acerca dos resultados que foram obtidos com o estudo, teve lugar a análise do Outono e Inverno (Tabela 18 e Figuras 10 e 11) a partir da distribuição da precipitação no respectivo trimestre do ano. 


\section{Precipitação Primavera}

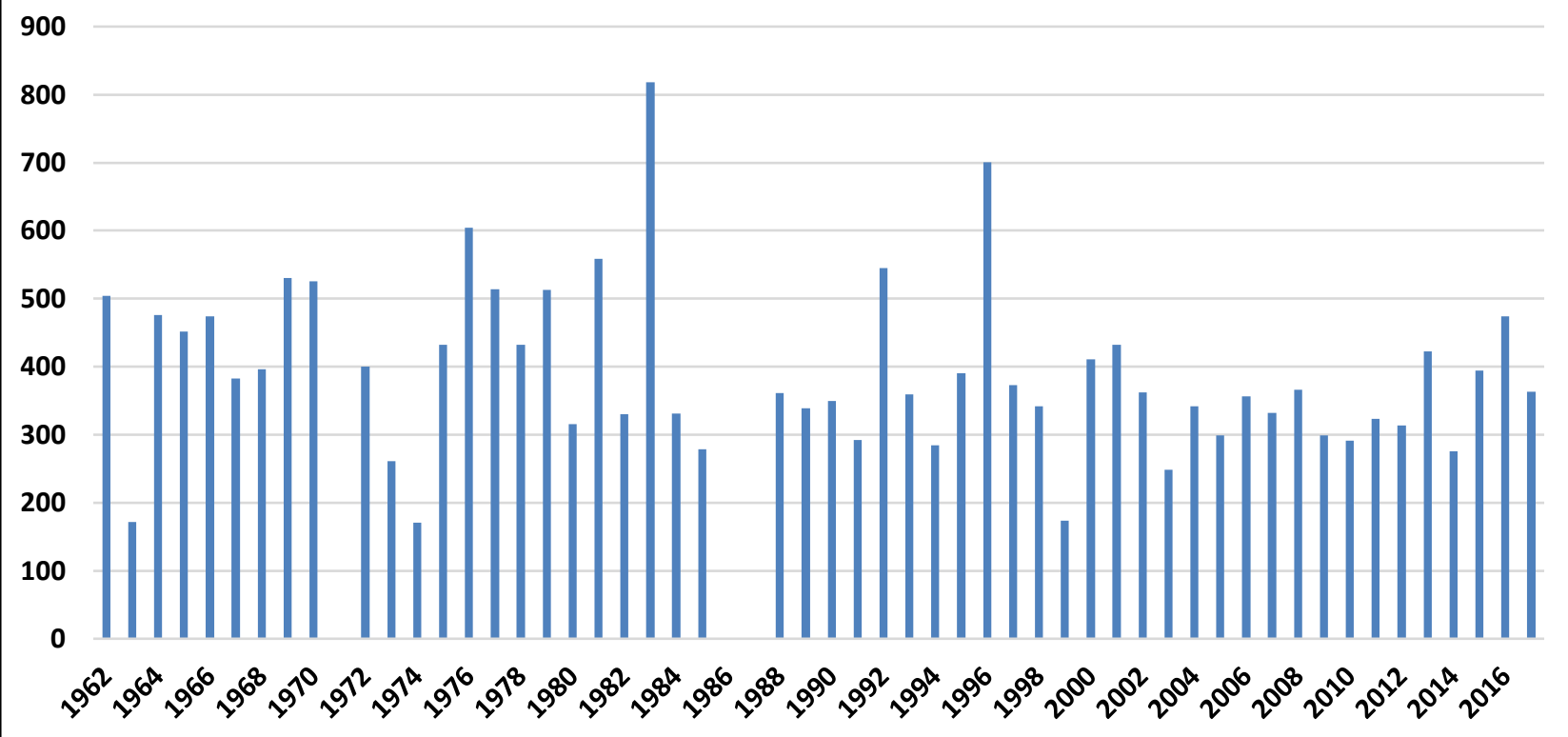

Figura 9 - Precipitação de primavera (trimestre) da série histórica 1962-2017.

Fonte - ANA (2018).

Tabela 17 - Frequência das Classes de Umidade para Primavera e Verão (trimestres) na Série Histórica 1962-2017.

\begin{tabular}{ccccccc}
\hline Classes & Primavera & $\%$ & Frequência & Verão & \% & Frequência \\
\hline C & $10 \mathrm{x}$ & $18,86 \%$ & $2^{\circ}$ & $12 \mathrm{x}$ & $22,22 \%$ & $2^{\circ}$ \\
TC & $7 \mathrm{x}$ & $13,20 \%$ & $4^{\mathrm{o}}$ & $8 \mathrm{x}$ & $14,81 \%$ & $4^{\circ}$ \\
N & $22 \mathrm{x}$ & $41,50 \%$ & $1^{\mathrm{o}}$ & $17 \mathrm{x}$ & $31,48 \%$ & $1^{\circ}$ \\
TS & $9 \mathrm{x}$ & $16,98 \%$ & $3^{\mathrm{o}}$ & $11 \mathrm{x}$ & $20,37 \%$ & $3^{\circ}$ \\
$\mathrm{S}$ & $5 \mathrm{x}$ & $09,43 \%$ & $5^{\mathrm{o}}$ & $6 \mathrm{x}$ & $11,11 \%$ & $5^{\circ}$ \\
\hline
\end{tabular}

\section{Precipitação Outono}

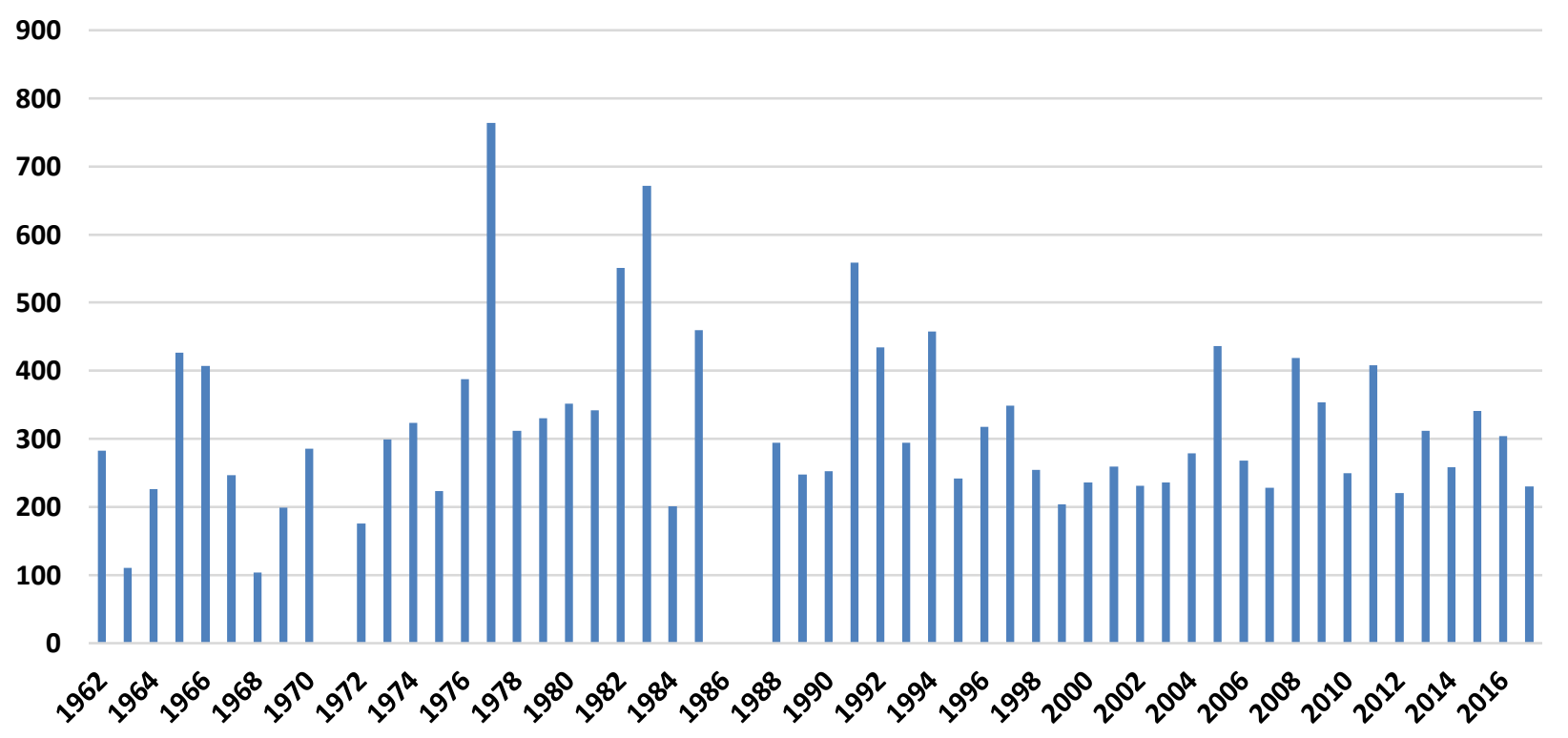

Figura 10 - Precipitação de outono (trimestre) da série histórica 1962-2017.

Fonte - ANA (2018). 
Conforme demonstram a Tabela 16 e as Figuras 10 e 11, o Outono e o Inverno iniciam a série com um volume médio de precipitação na primeira década, passando a seguir para um ganho no volume registrado que se estende por mais uma década (respeitada a transição entre as duas primeiras e depois frente a terceira). No entanto, a partir do final da década de oitenta, sofrem uma redução que se aproxima dos valores apresentados no período inicial da série.

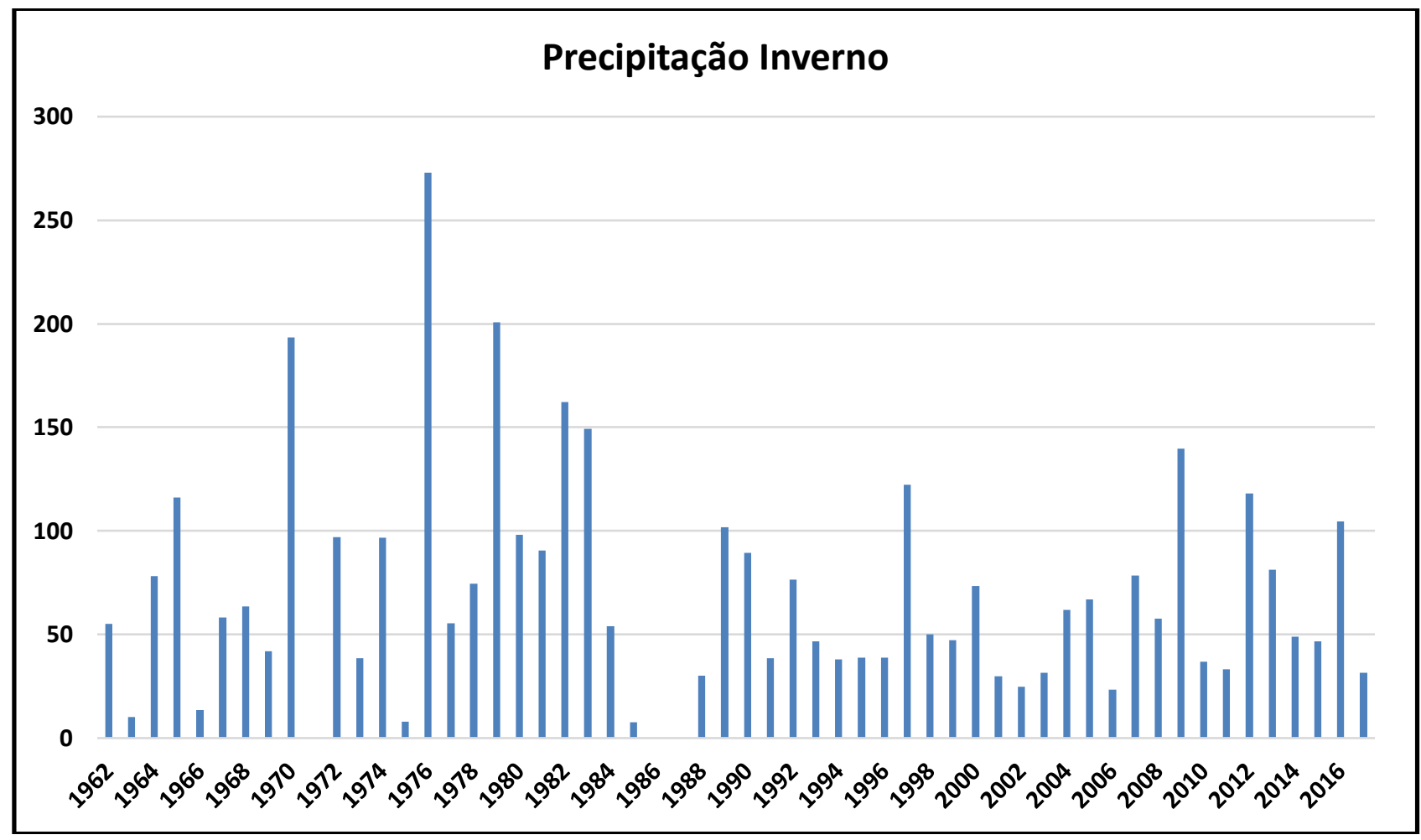

Figura 11 - Precipitação de inverno (trimestre) da série histórica 1962-2017.

Fonte - ANA (2018).

É difícil afirmar que a redução ou o pico do segundo quartel sejam cíclicos ou denunciem um momento de reordenação das variáveis atmosféricas rumo a um novo patamar no padrão climático da área; no entanto, causa preocupação a percepção de que o trimestre que responde especificamente pelo Inverno (seção trimestral com o menor índice pluviométrico do ano) esteja apresentando desde o final da década de oitenta uma redução que se encontra abaixo dos valores observados no início da série, pois, constitui o momento de maior carência hídrica do ano e sinaliza para o entendimento anterior de que a precipitação da área esteja passando por um processo prejudicial de concentração ao longo do ano, aumentando a intensidade dos efeitos deletérios causados pela estiagem.

Por seu turno, o Outono assemelha-se a Primavera e segue com as características de momento transitório onde os benefícios do Verão cooperam com o índice pluviométrico que apresentam, alcançando, por exemplo, no grupo de médias trimestrais, respectivamente 20,68\% e $25,38 \%$. O Inverno responde por apenas 4,71\% desse total, enquanto que o Verão chega a 49,22\%. 
Analisando a Tabela 18 é possível observar a distribuição da precipitação dos trimestres responsáveis pelo Outono e Inverno dentro dos parâmetros estabelecidos pelas cinco classes adotadas.

Tabela 18 - Frequência das Classes de Umidade para Outono e Inverno (trimestres) na Série Histórica 1962-2017.

\begin{tabular}{ccccccc}
\hline Classes & Outono & $\%$ & Frequência & Inverno & $\%$ & Frequência \\
\hline C & $12 \mathrm{x}$ & $22,64 \%$ & $2^{\mathrm{o}}$ & $16 \mathrm{x}$ & $30,18 \%$ & $2^{\circ}$ \\
$\mathrm{TC}$ & $4 \mathrm{x}$ & $07,54 \%$ & $4^{\mathrm{o}}$ & $1 \mathrm{x}$ & $01,88 \%$ & $5^{\circ}$ \\
$\mathrm{N}$ & $17 \mathrm{x}$ & $32,07 \%$ & $1^{\mathrm{o}}$ & $8 \mathrm{x}$ & $15,09 \%$ & $3^{\circ}$ \\
$\mathrm{TS}$ & $14 \mathrm{x}$ & $26,41 \%$ & $3^{\mathrm{o}}$ & $8 \mathrm{x}$ & $15,09 \%$ & $3^{\circ}$ \\
$\mathrm{S}$ & $6 \mathrm{x}$ & $11,32 \%$ & $5^{\mathrm{o}}$ & $20 \mathrm{x}$ & $37,73 \%$ & $1^{\circ}$ \\
\hline
\end{tabular}

Alterando o comportamento padrão dos trimestres de transição - Primavera e Outono - e do Verão, o Inverno inaugura o predomínio dos extremos com cerca de $68 \%$ dos anos situados nas classes Chuvoso e Seco, algo inusitado até então que caracteriza toda a volatilidade do período e a baixa influência da habitualidade no trimestre.

Tabela 19 - Principais Classes e seus Anos Representativos para os Trimestres - Primavera, Verão, Outono e Inverno na Série Histórica 1962-2017.

\begin{tabular}{ccccc}
\hline \multirow{2}{*}{ PRIMAVERA } & $\begin{array}{c}\text { CHUVOSO } \\
(1993)\end{array}$ & NORMAL & SECO & MÉDIA \\
& $817,7 \mathrm{~mm}$ & $366,3 \mathrm{~mm}$ & $(1974)$ & $(1962-2017)$ \\
& CHUVOSO & NORMAL & $170,2 \mathrm{~mm}$ & $369,36 \mathrm{~mm}$ \\
VER̃̃O & $(2006-07)$ & $(2001-02)$ & SECO & MÉDIA \\
& $1.067,4 \mathrm{~mm}$ & $714,5 \mathrm{~mm}$ & $85,5 \mathrm{~mm}$ & $(1962-2017)$ \\
& CHUVOSO & NORMAL & SECO & $716,28 \mathrm{~mm}$ \\
\multirow{2}{*}{ OUTONO } & $(1977)$ & $(1973)$ & $(1968)$ & MÉDIA \\
& $764,3 \mathrm{~mm}$ & $299,2 \mathrm{~mm}$ & $103,3 \mathrm{~mm}$ & $300,96 \mathrm{~mm}$ \\
& CHUVOSO & NORMAL & SECO & MÉDIA \\
& $(1979)$ & $(2005)$ & $(1985)$ & $(1962-2017)$ \\
INVERNO & $200,8 \mathrm{~mm}$ & $66,9 \mathrm{~mm}$ & $7,5 \mathrm{~mm}$ & $68,62 \mathrm{~mm}$ \\
& & & & \\
\hline
\end{tabular}

Com essa constatação, seguiu a análise trimestral da segunda metade da série histórica que é fornecida pelo INMET (2018) para os anos 1991-2017. Nessa seção de vinte e sete anos (Tabela 20) foi avaliada a tendência de intensificação da oscilação em detrimento da habitualidade, permitindo assim a complementação do diagnóstico que vem sendo redigido sobre a área.

Mais uma vez as séries apresentam índices próximos. Respectivamente as médias de cada trimestre segundo os dados fornecidos pela ANA (2018) e INMET (2018) foram respectivamente: Verão 716,28mm e 717,33mm, Primavera 369,36mm e 361,70mm, Outono 300,96mm e 310,37mm, e, Inverno 68,62mm e 58,73mm. Desta forma, a precipitação média foi maior na estação do INMET 
em 1,05mm no Verão e 9,41 mm no Outono, enquanto que os dados médios da estação da ANA foram maiores em 7,66mm na Primavera e 9,89 no Inverno; demonstrando, como o Verão - período úmido - apresenta maior estabilidade até mesmo entre os locais de captação de dados, enquanto que o Inverno nesse quesito também se destaca pela oscilação.

Certamente o conjunto de dados assegura que os mecanismos que atuam na formação das chuvas permanecem praticamente inalterados conferindo aos índices a normalidade esperada, algo que não é visto no período seco ou menos úmido, em razão da oscilação permanente que apresenta e repercute sobre a paisagem através da oferta hídrica e da resposta da vegetação e cursos d'água.

Segundo demonstram as Figuras a seguir (12, 13, 14 e 15), cada estação do ano - trimestre - possui uma distribuição de anos abaixo ou acima da média, demonstrando que cada seção possui suas características próprias frente as demais, ainda que no contexto anual estejam harmonizadas com as características dos climas monçônicos que possuem um período úmido e outro seco.

Tabela 20 - Precipitação nas Estações do Ano na série histórica 1991-2917.

\begin{tabular}{ccccc}
\hline ANO & VER ÃO & PRIMAVERA & OUTONO & INVERNO \\
\hline 1991 & 1034,70 & 291,70 & 558,60 & 38,50 \\
1992 & 887,50 & 544,80 & 433,90 & 76,40 \\
1993 & 568,20 & 359,30 & 293,90 & 46,70 \\
1994 & 904,60 & 284,50 & 457,80 & 38,00 \\
1995 & 643,60 & 390,50 & 242,00 & 38,90 \\
1996 & 812,10 & 700,40 & 317,30 & 38,70 \\
1997 & 602,50 & 373,30 & 348,40 & 122,20 \\
1998 & 947,40 & 341,40 & 254,80 & 50,20 \\
1999 & 927,30 & 173,60 & 203,70 & 47,30 \\
2000 & 474,40 & 411,20 & 236,00 & 73,50 \\
2001 & 714,50 & 432,30 & 259,70 & 29,90 \\
2002 & 574,90 & 362,40 & 231,00 & 24,70 \\
2003 & 838,80 & 248,50 & 236,30 & 31,50 \\
2004 & 857,00 & 341,80 & 278,30 & 61,80 \\
2005 & 685,10 & 299,40 & 436,00 & 66,90 \\
2006 & 1067,40 & 355,90 & 268,10 & 23,40 \\
2007 & 515,20 & 332,20 & 228,00 & 78,60 \\
2008 & 819,60 & 366,30 & 418,90 & 57,70 \\
2009 & 699,90 & 299,30 & 353,40 & 139,80 \\
2010 & 837,20 & 291,00 & 249,60 & 36,80 \\
2011 & 667,60 & 323,20 & 408,20 & 33,10 \\
2012 & 1049,60 & 313,50 & 220,40 & 118,20 \\
2013 & 304,10 & 422,80 & 311,60 & 81,20 \\
2014 & 640,30 & 275,90 & 258,80 & 49,00 \\
2015 & 758,40 & 394,40 & 340,90 & 46,70 \\
2016 & 319,20 & 473,50 & 303,80 & 31,60 \\
2017 & 216,90 & 362,70 & 230,60 & \\
\hline
\end{tabular}

Fonte - INMET (2018).

Segundo a Figura 12 demonstra, nos últimos anos da série a precipitação nesse trimestre do ano esteve abaixo da média de forma bem pronunciada, apresentando os dois índices mais negativos do período acompanhados pelo quarto pior desempenho das chuvas. 


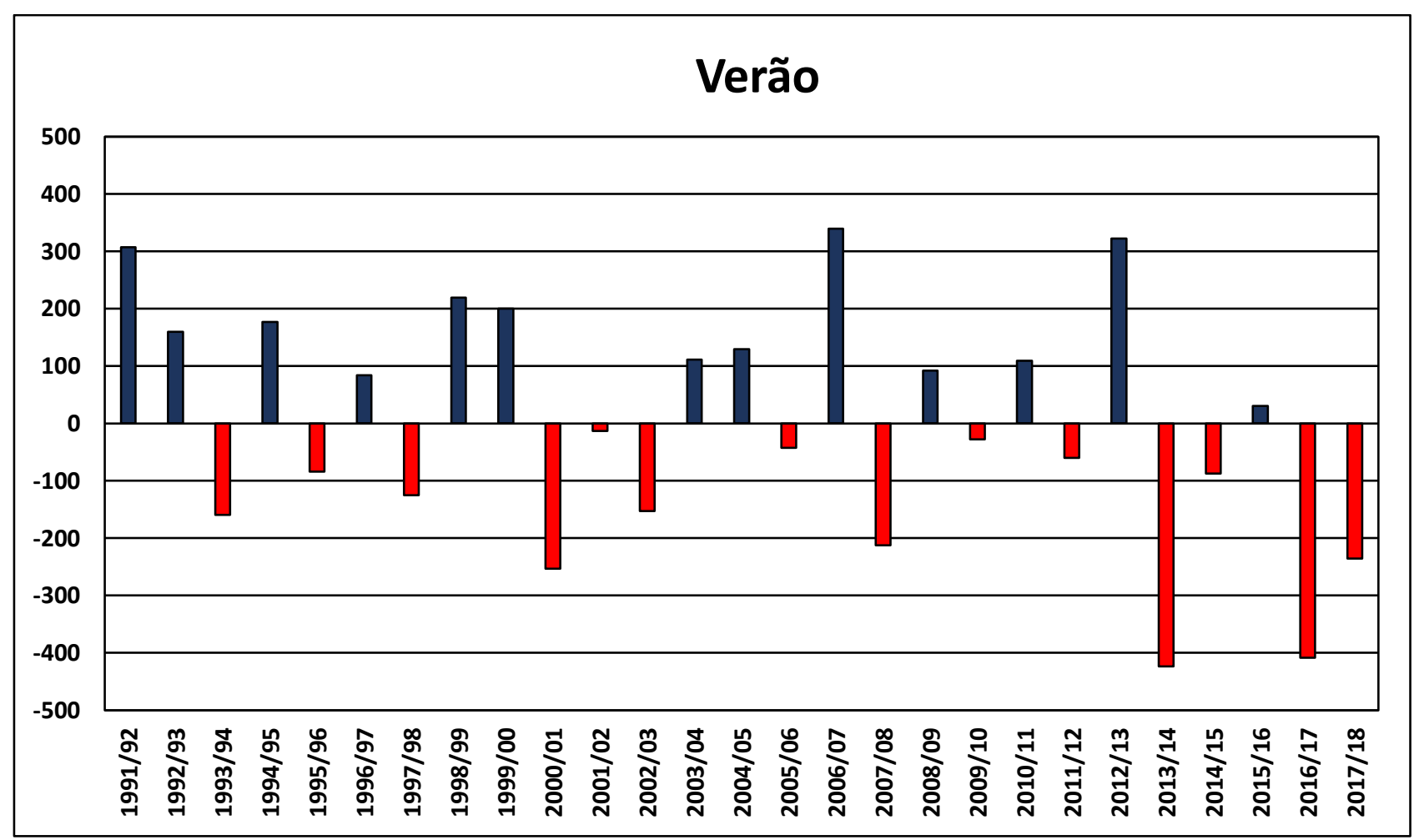

Figura 12 - Precipitação de verão (trimestre) da série histórica 1991-2017.

Fonte - INMET (2018).

Cumpre observar que nesses últimos anos da série a perda de precipitação alcançou volume total superior a $1.100 \mathrm{~mm}$, agravando, consequentemente o cenário da área, uma vez que a carência experimentada por plantas e cursos d'água nesse período do ano deve ter agravado o estresse do período mais seco, sobretudo no Inverno.

No caso da Primavera, verificou-se uma outra situação, onde o predomínio de anos com índices pluviométricos abaixo da média foi seguido por um aparente momento de maior pluviosidade. Infelizmente, as chuvas dos últimos anos da série forneceram pouco excedente frente a década de déficits que lhes antecedeu. Aliás, os anos mais úmidos do final da série estão abaixo dos maiores valores registrados em 1992 e 1996, algo que fica agravado quando se verifica que os anos com precipitação abaixo da média chegam a treze enquanto que chegam a oito os anos com índices acima. Seis anos apresentam índices próximos a média histórica e se distribuem ao longo da série. Diante disto, a diminuição da oferta hídrica na área fica evidenciada, mesmo que o quadro não seja caótico e esteja distante dos parâmetros de um clima semiárido. 


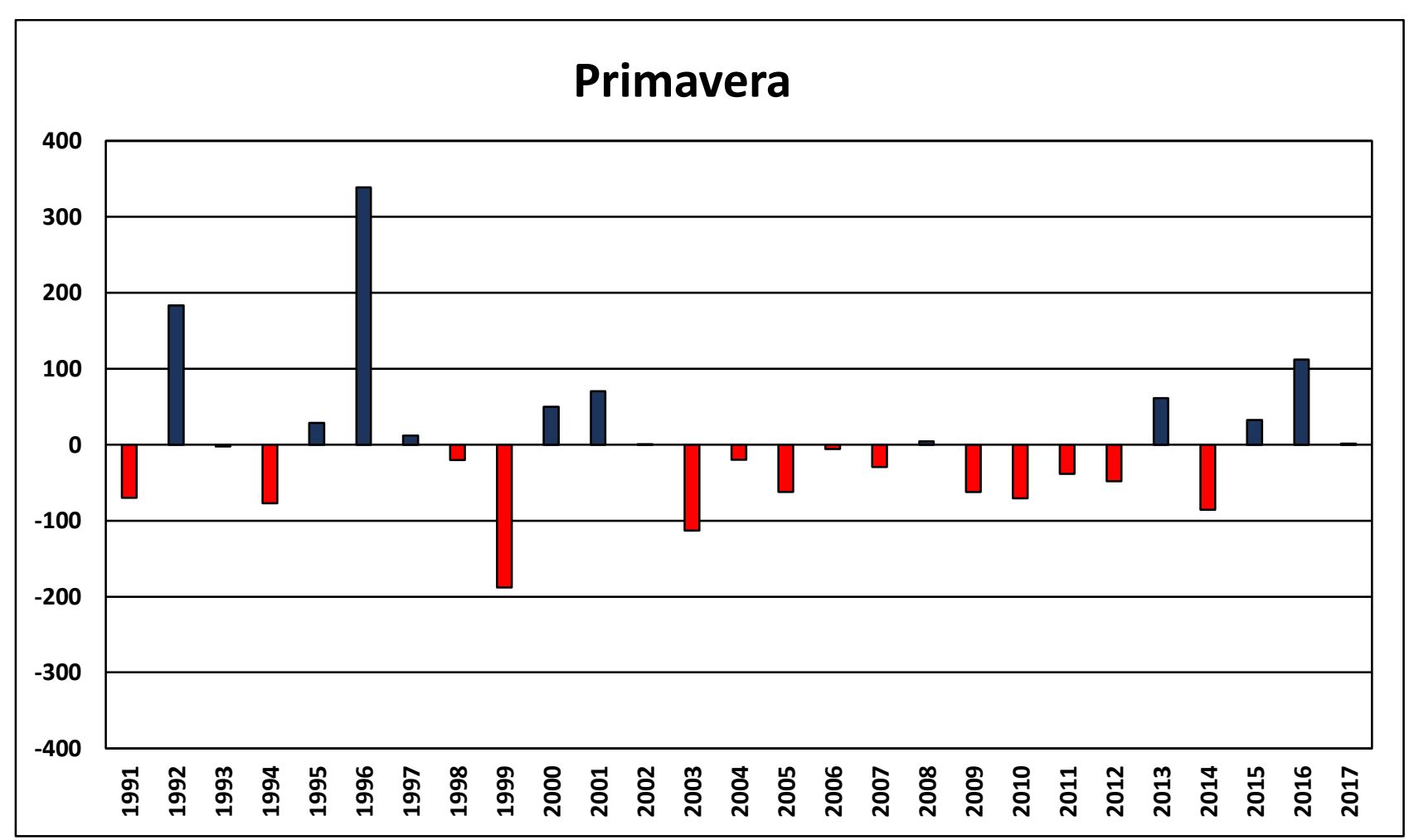

Figura 13 - Precipitação de primavera (trimestre) da série histórica 1991-2017.

Fonte - INMET (2018).

A Tabela 21 demonstra mais uma vez que a normalidade prevalece nesses trimestres em correspondência com a habitualidade que se verifica nos semestres chuvosos formados pelos mesmos. Obviamente, as expressões "habitualidade" ou "normalidade" dizem respeito ao padrão característico verificado na série histórica que se manifesta na forma de uma precipitação mais abundante e próxima dos índices médios da seção anual.

Tabela 21 - Frequência das Classes de Umidade para Primavera e Verão (trimestres) na Série Histórica 1991-2017.

\begin{tabular}{ccccccc}
\hline Classes & Primavera & $\%$ & Frequência & Verão & $\%$ & Frequência \\
\hline C & $3 \mathrm{x}$ & $11,11 \%$ & $3^{\circ}$ & $4 \mathrm{x}$ & $14,81 \%$ & $3^{\circ}$ \\
TC & $2 \mathrm{x}$ & $7,40 \%$ & $4^{\mathrm{o}}$ & $6 \mathrm{x}$ & $22,22 \%$ & $2^{\circ}$ \\
N & $14 \mathrm{x}$ & $51,85 \%$ & $1^{\circ}$ & $9 \mathrm{x}$ & $33,33 \%$ & $1^{\circ}$ \\
TS & $6 \mathrm{x}$ & $22,22 \%$ & $2^{\circ}$ & $4 \mathrm{x}$ & $14,81 \%$ & $3^{\mathrm{o}}$ \\
$\mathrm{S}$ & $2 \mathrm{x}$ & $7,40 \%$ & $4^{\circ}$ & $4 \mathrm{x}$ & $14,81 \%$ & $3^{\text {o }}$ \\
\hline
\end{tabular}

Conforme demonstram os dados, a Primavera apresenta menos de um quinto de seus anos nas classes extremas de Anos Chuvosos ou Secos, enquanto o Verão possui quase trinta por cento dos anos nessa condição. Diante disto, excetuando-se a diminuição da precipitação na Primavera e a condição final do padrão pluviométrico no Verão, esse intervalo do ano mantém-se ainda na conjuntura habitual que historicamente prevalece sobre a área.

Na Figura 14 é apresentada a distribuição da chuva ao longo dos três meses de outono que antecedem ao inverno. 


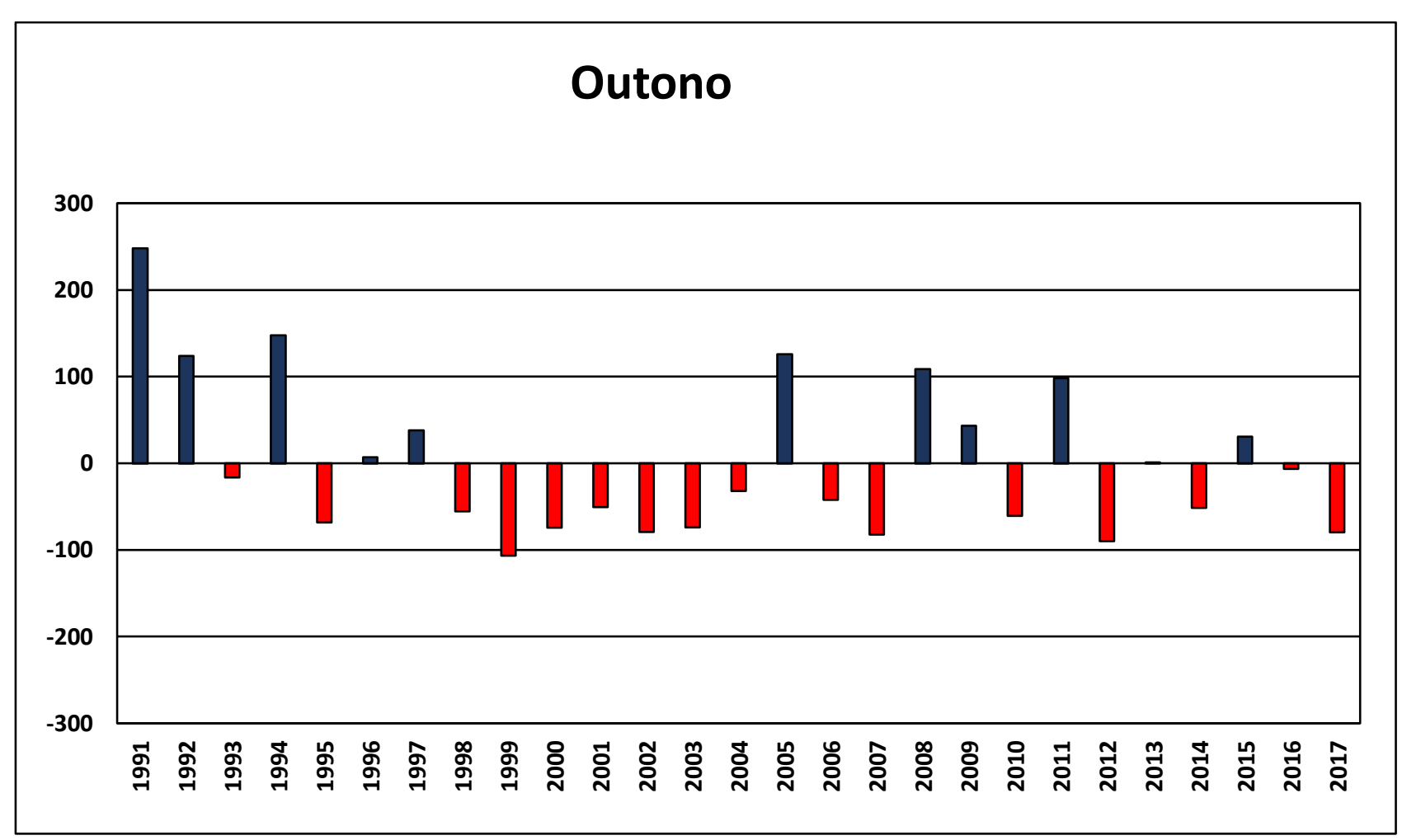

Figura 14 - Precipitação de outono (trimestre) da série histórica 1991-2017 Fonte - INMET (2018).

Por mais que cada trimestre tenha suas características e fatores intervenientes, respeitandose algumas diferenças, é possível observar no outono uma situação semelhante àquela verificada na primavera, pois, após um momento inicial de maior precipitação, segue-se uma série dominada pela diminuição das chuvas, mesmo que os quatorze anos com índices pluviométricos abaixo da média sejam intercalados amiúde por alguns poucos anos com chuvas acima da média. Ao todo são quatro anos classificados na condição mediana, nove mais úmidos e outros quatorze menos úmidos, sendo os três melhores índices de chuva encontrados dentre os quatro primeiros anos da série, outorgando aos próximos vinte e três anos os seis anos úmidos restantes que se observam.

Entre 1998 e 2004 os anos com precipitação abaixo da média prevalecem e passam a caracterizar o perfil da série histórica. A partir deste período seguem-se apenas dois anos medianos 2013 e 2016 - e cinco anos úmidos distribuídos entre os demais seis anos com chuvas abaixo da média, reduzindo de forma perceptível a contribuição de água para o acumulado anual e para os momentos de maior escassez do ano.

Finalmente, encerrando as considerações acerca do comportamento da precipitação ao longo do ano, segue-se a Figura 15 referente ao Inverno. 


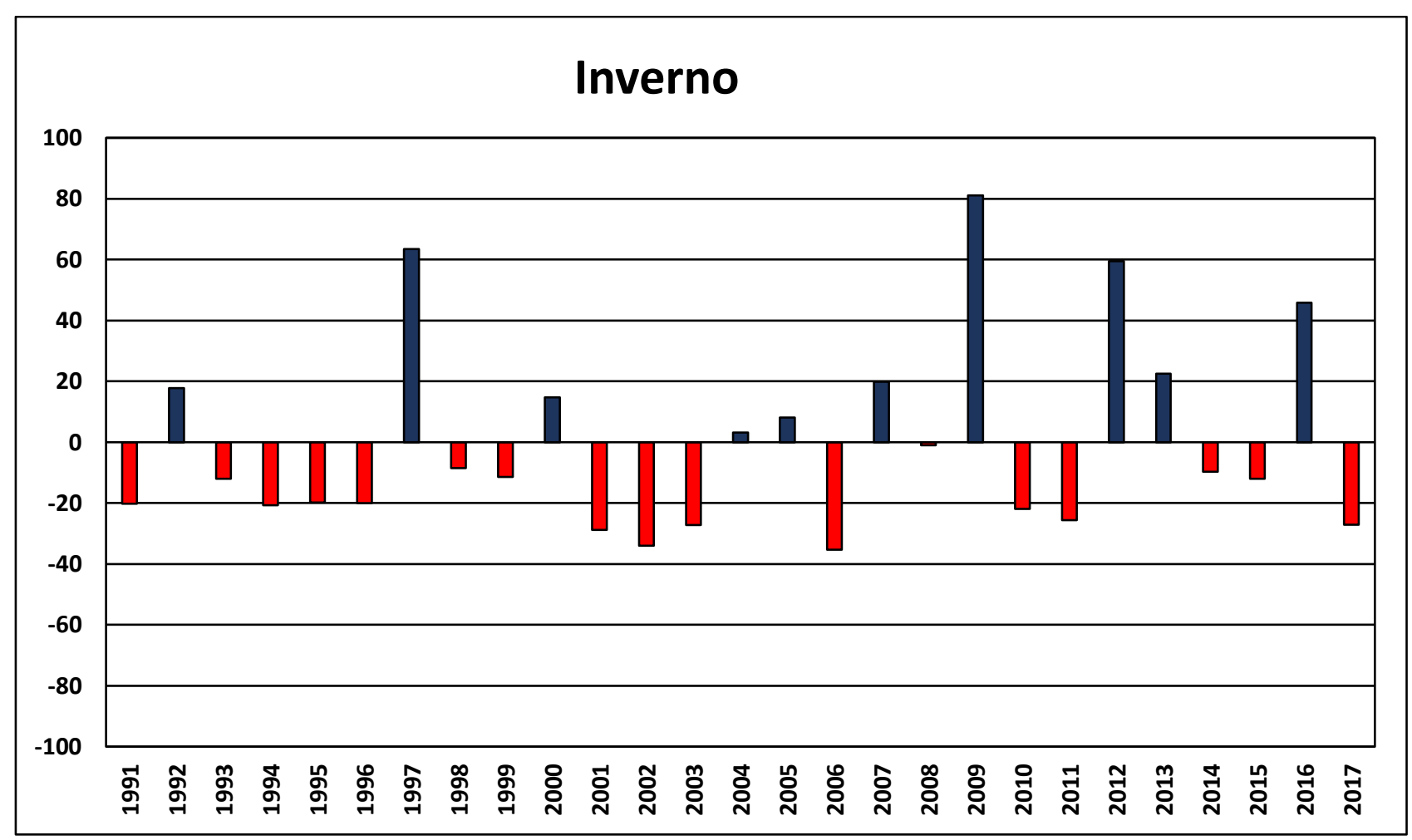

Figura 15 - Precipitação de inverno (trimestre) da série histórica 1991-2017. Fonte - INMET (2018).

Na Figura 15 é possível mais uma vez identificar o comportamento abrupto da precipitação nesse período do ano, pois, paralelo a alguns anos com um índice elevado para o padrão da estação, tem-se o predomínio dos anos com registros inferiores à média histórica do trimestre. Apenas dois meses alcançam pluviosidade semelhante à média. No total, são nove meses com precipitação acima da média e dezesseis abaixo. Em 1997, 2009, 2012 e 2016 a precipitação surpreendeu a área frente aos parâmetros esperados, mas, ainda assim, a série é dominada pelos anos com precipitação abaixo da média do período, evidenciando o ritmo inconstante que as chuvas apresentam nessa estação.

Pelo que pode ser observado, a instabilidade caracteriza o inverno da área ao longo da série histórica, enquanto que a estabilidade prevalece nos demais trimestres, amenizando essa característica do período seco.

Os dados da Tabela 22 também auxiliam na compreensão do comportamento da precipitação na área de estudo, demonstrando que a condição que prevalece no outono assemelha-se àquela que é observada na primavera e possui um padrão comum com o verão, pois, não chega a um terço da série o número de anos situados nas classes extremas adotadas, Anos Chuvosos ou Secos. Por seu turno, o inverno mantém-se no descompasso dessa estabilidade, mostrando-se permanentemente inconstante com cerca de dois terços de seus anos situados nas classes Anos Chuvosos e Secos. 
Tabela 22 - Frequência das Classes de Umidade para Outono e Inverno (trimestres) na Série Histórica 1991-2017.

\begin{tabular}{ccccccc}
\hline Classes & Outono & \% & Frequência & Inverno & $\%$ & Frequência \\
\hline $\mathrm{C}$ & $6 \mathrm{x}$ & $22,22 \%$ & $3^{\mathrm{o}}$ & $7 \mathrm{x}$ & $25,92 \%$ & $2^{\text {o }}$ \\
$\mathrm{TC}$ & - & - & - & $1 \mathrm{x}$ & $3,7 \%$ & $5^{\circ}$ \\
$\mathrm{N}$ & $9 \mathrm{x}$ & $33,33 \%$ & $2^{\mathrm{o}}$ & $4 \mathrm{x}$ & $14,81 \%$ & $3^{\text {o }}$ \\
$\mathrm{TS}$ & $11 \mathrm{x}$ & $40,74 \%$ & $1^{\mathrm{o}}$ & $4 \mathrm{x}$ & $14,81 \%$ & $3^{\mathrm{o}}$ \\
$\mathrm{S}$ & $1 \mathrm{x}$ & $3,7 \%$ & $4^{\mathrm{o}}$ & $11 \mathrm{x}$ & $40,74 \%$ & $1^{\text {o }}$ \\
\hline
\end{tabular}

Tabela 23 - Principais Classes e seus Anos Representativos para os Trimestres - Primavera, Verão, Outono e Inverno na Série Histórica 1991-2017.

\begin{tabular}{ccccc}
\hline \multirow{2}{*}{ PRIMAVERA } & $\begin{array}{c}\text { CHUVOSO } \\
(1996)\end{array}$ & $\begin{array}{c}\text { NORMAL } \\
(2002)\end{array}$ & $\begin{array}{c}\text { SECO } \\
(1999)\end{array}$ & MÉDIA \\
& $700,4 \mathrm{~mm}$ & $362,4 \mathrm{~mm}$ & $173,6 \mathrm{~mm}$ & $361,6 \mathrm{~mm}$ \\
& CHUVOSO & NORMAL & SECO & MÉDIA \\
VERÃO & $(2006-07)$ & $(2001-02)$ & $(2013-14)$ & $(1991-2017)$ \\
& $1.067,4 \mathrm{~mm}$ & $714,5 \mathrm{~mm}$ & $304,1 \mathrm{~mm}$ & $727,5 \mathrm{~mm}$ \\
& CHUVOSO & NORMAL & SECO & MÉDIA \\
\multirow{2}{*}{ OUTONO } & $(1991)$ & $(2013)$ & $(1999)$ & $(1991-2017)$ \\
& $558,6 \mathrm{~mm}$ & $311,6 \mathrm{~mm}$ & $203,7 \mathrm{~mm}$ & $310,3 \mathrm{~mm}$ \\
& CHUVOSO & NORMAL & SECO & MÉDIA \\
INVERNO & $(2009)$ & $(2008)$ & $(2006)$ & $(1991-2017)$ \\
& $139,8 \mathrm{~mm}$ & $57,7 \mathrm{~mm}$ & $23,4 \mathrm{~mm}$ & $58,7 \mathrm{~mm}$ \\
\hline
\end{tabular}

Naturalmente os extremos observados no inverno encontram-se muito bem inseridos no comportamento atmosférico da área, representando um momento peculiar em que as variáveis climatológicas atuam de maneira específica a ponto de estabelecer uma conjuntura diferenciada que a partir da primavera deixa de existir para retornar apenas ao final do outono, nove meses depois, portanto, por indesejáveis que sejam, essas variáveis encontram-se inseridas no conjunto de forças que atuam sobre a atmosfera em escalas global, regional e local, criando as condições particulares que se manifestam nesse único trimestre do ano.

\section{CONSIDERAÇÕES FINAIS}

Frente ao que foi exposto nas páginas anteriores, é possível tecer nessa seção do texto alguns comentários que resgatam o diagnóstico redigido aqui e acolá ao longo dos parágrafos anteriores, cooperando com a melhor descrição do comportamento da precipitação na área e com a visualização das características que prevalecem no seu território, permitindo, por conseguinte, uma melhor articulação com as sugestões que são apresentadas para benefício da sociedade e meio ambiente locais, sobretudo porque, ficam explícitas algumas constatações à luz dos dados analisados. 
Em primeiro lugar, pode-se dizer que independentemente da estação meteorológica Agência Nacional de Águas e Instituto Nacional de Meteorologia - ou do tamanho da série - 19622017 e 1991-2017 - de anos considerada na análise, fica notório para qualquer leitor desse trabalho a existência de duas conjunturas atmosféricas ao longo do ano; uma pautada pela constância do comportamento da precipitação, e, outra pela permanente oscilação.

Também fica explícito que os processos atuantes sobre o verão, primavera e outono são mais regulares que aqueles que atuam sobre o inverno. Aliás, a diferença do comportamento da precipitação no verão frente ao que ocorre no outono e na primavera reside quase que exclusivamente no volume da pluviosidade, pois a regularidade lhes é comum frente aos dados que apresentam ao longo da série histórica. Apenas o inverno apresenta condição diferente que salta aos olhos.

Provavelmente a condição do trimestre seco do ano esteja relacionada ao embate que é mantido nesse período entre as massas de ar que atuam na área. Nos anos em que os processos frontogenéticos ou a Zona de Convergência do Atlântico Sul conseguem superar o bloqueio atmosférico imposto pela ação da Massa Tropical Continental, prevalecem as condições favoráveis a formação de chuva, proporcionando um volume de chuva sobre a área que ameniza a escassez de precipitação apesar de pequeno frente aos parâmetros observados noutras estações do ano.

Certamente, nos anos em que o bloqueio atmosférico estabelecido pela massa de ar supracitada é mais forte, as chuvas tornam-se escassas, ocasionando significativa redução na disponibilidade de recursos hídricos na área.

Diante disto, fica evidente que a ação das massas de ar Polar Atlântica (mPa), Tropical Atlântica (mTa) e Equatorial Continental $(\mathrm{mEc})$ cooperam para a formação de chuvas e o input hídrico da área, enquanto que o protagonismo da massa Tropical Continental (mTc) responde pelas condições de estabilidade que impedem a formação de chuvas.

Com essa compreensão, um quadro do padrão atmosférico na área de estudo vai se consolidando de forma a permitir uma eficiente estratégia de compensação que assegure o suprimento ininterrupto de água o ano todo sem prejuízo do meio ambiente e esgotamento do recurso. Para isso, basta que haja um programa abrangente que estimule o uso racional dos recursos hídricos e contemple o padrão de atuação dessas massas de ar ao longo do ano, prevendo armazenamento nos momentos em que os índices são elevados e o uso adequado nos períodos de carência.

Tal iniciativa passa pela elaboração de um EIA/RIMA que se ocupe do inventário das características ambientais da área e das atividades antrópicas, para municiamento dos planos e estratégias preconizados de forma a mitigar os impactos ocasionados pela escassez do recurso hídrico no período de estiagem, sem, contudo, prejudicar o funcionamento do ecossistema local ou a qualidade de vida da população. 
Como estudos dessa envergadura recobram um tempo significativo para serem desenvolvidos a contento, cumpre que as autoridades, setores da sociedade organizada, empreendedores e governança locais arregacem as mangas da camisa e se lancem o quanto antes a esse árduo trabalho, pois, quer seja por retorno cíclico no padrão atmosférico da área ou por mudanças climáticas que se anunciam para o futuro próximo, fato é que passa a haver uma ligeira redução nos índices de precipitação anual na área, com o agravante de concentração das chuvas em determinados períodos do ano, aumentando, por conseguinte o hiato de tempo com carência hídrica.

\section{AGRADECIMENTOS}

Os autores agradecem o apoio e subsídios fornecidos tanto pela Agência Regional de Proteção Ambiental da Bacia do Rio Grande (ARPA) que financiou o Projeto "Diagnóstico geoambiental da APA da bacia hidrográfica do rio Machado/MG", como pelo Instituto Estadual de Florestas (IEF) e da Universidade Federal de Alfenas (UNIFAL-MG).

\section{NOTA DOS AUTORES}

O presente artigo, juntamente com o artigo "O estudo do comportamento da temperatura em Machado/MG entre 1991 e 2017 e a influência exercida pela precipitação sazonal nesse processo" foram reunidos em um capítulo de livro que estará compondo o Relatório Final do Projeto "Diagnóstico geoambiental da APA da bacia hidrográfica do rio Machado/MG" que foi desenvolvido em parceria pela UNIFAL-MG, IEF e ARPA (supracitados acima). Os artigos destinam-se ao mundo acadêmico, enquanto o Relatório para as autoridades municipais e população local.

\section{REFERÊNCIAS}

AGÊNCIA NACIONAL DE ÁGUAS - Portal HidroWeb. Disponível em http://www.snirh.gov.br/hidroweb/publico/medicoes_historicas_abas.jsf. Acesso em: 10 abr. 2018.

ANDRÉ, Í. R. N. Algumas considerações sobre mudanças climáticas e eventos atmosféricos severos recentes no Brasil. Climatologia e Estudos da Paisagem, v. 1, p. 01-09, 2006.

BARBOSA, J. P. M. Mudanças climáticas e distribuição espacial da precipitação na Serra do Mar análise a partir de séries históricas de precipitação e sistemas de informação geográfica (SIG). Caminhos da Geografia, Uberlândia, v. 8, p. 67-81, 2007.

BRAIDO, L. M. H.; TOMMASELLI, J. T. G. Caracterização climática e dos anos extremos (chuvoso e seco): seus efeitos na produção de cana-de-açúcar, milho e soja para a região do Pontal do Paranapanema-SP. Revista Formação, v. 1, p. 13-34, 2010.

CARMO R. L.; ANAZAWA, T. M.; JOHANSEN, I. C. Seca nas metrópoles: materialização de um desastre anunciado. Waterlat-Gobacit Network Working Papers - Thematic Area Series SATAD - TA8 - Water-related Disasters, v. 1, p. 91-109, 2014.

DINIZ, D. T. Delimitação e Classificação mineralógica/petrográfica das atividades extrativistas minerais da microrregião de Alfenas-MG. 2016. 96 f. Monografia (Trabalho de Graduação em Geografia) - Curso de Geografia Bacharelado, Universidade Federal de Alfenas, Alfenas, 2016. 
FUNDAÇÃO DE PESQUISA E ASSESSORAMENTO À INDUSTRIA. Plano Diretor de Recursos Hídricos da Bacia Hidrográfica do Entorno do Lago de Furnas: Relatório Parcial 1 Diagnóstico da Bacia Hidrográfica Unidade de Gestão GD3. Alfenas, 2013.

INSTITUTO NACIONAL DE METEOROLOGIA. Disponível em http://www.inmet.gov.br/portal/index.php?r=bdmep/bdmep. Acesso em: 11 de abr. 2018.

KÖPPEN, W.; GEIGER, R. Klimate der Erde. Gotha: Verlag Justus Perthes, 1928. Wallmap 150cm $\mathrm{x} 200 \mathrm{~cm}$.

MONTEIRO, C. A. F. O Clima e a organização do espaço no Estado de São Paulo: problemas e perspectivas. São Paulo: IGEOG/USP (Série Teses e Monografias - 28), 1976. 54p.

Clima e Excepcionalidade: conjunturas sobre o desempenho da atmosfera como fenômeno climático. 1. ed. Florianópolis: UFSC, 1991. 233p.

MOURA, M. O.; ZANELLA, M. E. Escolha de "Anos-Padrão" para o estudo do conforto térmico em Fortaleza, CE: verificação de critérios. Revista Geonorte, v. 1, p. 547-560, 2012.

NIMER, E. Climatologia do Brasil. 1. ed. Rio de Janeiro: IBGE, Rio de Janeiro, 1979. 422p.

SÁ JUNIOR, A. Aplicação da classificação de Köppen para o zoneamento climático do Estado de Minas Gerais. 2009. 101 f. Dissertação (Mestrado em Engenharia de Água e Solo) - Programa de Pós-Graduação em Engenharia Agrícola, Universidade Federal de Lavras, Lavras, 2009.

SEnTElHAS, P. C.; PEREIRA, A. L. Meteorologia Agrícola. 1. ed. Piracicaba: ESALQ, 2000. $172 \mathrm{p}$.

SIQUEIRA, O. J. F.; FARIAS, J. R. B.; SANS, L. M. A. Potential effects of global climate change for brazilian agriculture: applied simulations studies for wheat, maize and soybeans. In: ROSENZWEIG, C., IGLESIAS, A. (Org.). Implications for climate change for international agriculture: crop modeling study. Washington: EPA, 1994. p. 117-135.

SILVA, J. M. O.; SILVA, E. V. Utilização dos anos padrões para a caracterização pluviométrica na bacia hidrográfica do rio Pirangi/Ceará. Revista Geonorte, v. 3, p. 1358-1369, 2012.

SOARES, L. P.; ZANELLA, M. E. Eleição de anos-padrão para a caracterização climática do Estado do Ceará. In: X SIMPÓSIO BRASILEIRO DE CLIMATOLOGIA GEOGRÁFICA, X., 2010, Curitiba. Anais... Curitiba: 2014, p. 2468-2479;

TAVARES, A. C. Critérios de escolha de anos padrões para análise rítmica. Revista Geografia, v.1, p. 79-89, 1976. 